\title{
Progress in Genetic Studies of Tourette's Syndrome
}

\author{
Yanjie Qi ${ }^{1,2}$, Yi Zheng ${ }^{2,3}$, Zhanjiang $\mathrm{Li}^{2,3}$ and Lan Xiong ${ }^{1,4,5, *}$ \\ 1 Laboratoire de Neurogénétique, Centre de Recherche, Institut Universitaire en Santé Mentale de Montréal, \\ Montreal, QC H1N 3V2, Canada; qijie416@126.com \\ 2 Beijing Key Laboratory of Mental Disorders, Beijing Anding Hospital, Capital Medical University, \\ Beijing 100088, China; yizheng@ccmu.edu.cn (Y.Z.); lizhanjiang1221@sina.com (Z.L.) \\ 3 Center of Schizophrenia, Beijing Institute for Brain Disorders, Beijing 100088, China \\ 4 Département de Psychiatrie, Faculté de Médecine, Université de Montréal, Montreal, QC H3C 3J7, Canada \\ 5 Department of Neurology and Neurosurgery, McGill University, Montreal, QC H3A 2B4, Canada \\ * Correspondence: lan.xiong@umontreal.ca; Tel.: +1-514-251-4000 (ext. 3415); Fax: +1-514-251-2617
}

Received: 1 August 2017; Accepted: 17 October 2017; Published: 20 October 2017

\begin{abstract}
Tourette's Syndrome (TS) is a complex disorder characterized by repetitive, sudden, and involuntary movements or vocalizations, called tics. Tics usually appear in childhood, and their severity varies over time. In addition to frequent tics, people with TS are at risk for associated problems including attention deficit hyperactivity disorder (ADHD), obsessive-compulsive disorder (OCD), anxiety, depression, and problems with sleep. TS occurs in most populations and ethnic groups worldwide, and it is more common in males than in females. Previous family and twin studies have shown that the majority of cases of TS are inherited. TS was previously thought to have an autosomal dominant pattern of inheritance. However, several decades of research have shown that this is unlikely the case. Instead TS most likely results from a variety of genetic and environmental factors, not changes in a single gene. In the past decade, there has been a rapid development of innovative genetic technologies and methodologies, as well as significant progresses in genetic studies of psychiatric disorders. In this review, we will briefly summarize previous genetic epidemiological studies of TS and related disorders. We will also review previous genetic studies based on genome-wide linkage analyses and candidate gene association studies to comment on problems of previous methodological and strategic issues. Our main purpose for this review will be to summarize the new genetic discoveries of TS based on novel genetic methods and strategies, such as genome-wide association studies (GWASs), whole exome sequencing (WES) and whole genome sequencing (WGS). We will also compare the new genetic discoveries of TS with other major psychiatric disorders in order to understand the current status of TS genetics and its relationship with other psychiatric disorders.
\end{abstract}

Keywords: Tourette Syndrome; gene mapping; genetic association; genetic linkage; complex trait; heritability; epigenetic; genome-wide association study; whole exome sequencing; whole genome sequencing

\section{Introduction and Genetic Epidemiology of Tourette's Syndrome}

\subsection{Clinical Features of Tourette's Syndrome}

Tourette's Syndrome (TS) is a complex neuropsychiatric and developmental disorder characterized by repetitive, sudden, involuntary movements and vocalizations, called tics. Vocal tics demonstrated as the involuntary outburst of obscene words, or socially inappropriate and derogatory remarks, called coprolalia, are rare (in about $8 \%$ of TS patients) according to the Diagnostic and Statistical Manual of Mental Disorders, Fifth Edition (DSM-5) [1]. TS is the most serious form of a spectrum of tic disorders [1], not only due to its complexity and duration of tic symptoms, but also due to its higher comorbidity, impairment of social function and compromised quality of life [2]. In TS, 
tics typically start at 4-6 years old; and the severity peaks around 10-12 years old [3]. The course of TS waxes and wanes [4]. Tic symptoms increase during times of stress, anxiety, fatigue and decrease with focused concentration, such as processing fine motor movements [5]. For long-term clinical course, tic symptoms gradually ease during adolescence. Until early adulthood, approximately $75 \%$ of patients have a different degree of decreased tic symptoms, including one-third of patients with complete remission; but a quarter of patients continue to have tics in adulthood [3], which has been shown to be correlated with the severity of tics in late childhood [6,7]. Studies have also shown that comorbidities presented at the onset showed a more severe prognosis [6,8,9]. In addition, poor fine-motor skills and smaller caudate volume in childhood were found to be associated with increased adulthood tic severity $[10,11]$. These may represent different subtypes of TS, and need to be taken into consideration when planning genetic studies to identify the underlying causes.

\subsection{Comorbidities of TS}

As one of the prominent characteristics compared to other neuropsychiatric disorders, TS is most often associated with other mental and behavioral symptoms and psychiatric diagnoses [12,13], such as obsessions, compulsions, hyperactivity, distractibility, and impulsivity. Studies have shown that $88-92 \%$ of TS patients also suffer from one or more comorbidities, such as attention deficit hyperactivity disorder (ADHD), obsessive-compulsive disorder (OCD), Non-OCD anxiety disorders, mood disorders, disruptive behavior disorders, pervasive developmental disorders and problems with sleep [12,14-16]. A significant subset of children with TS also have fine motor control and visual-motor integration impairment. The most common age for comorbidity occurrence is around 4-10 years old, except for eating disorder and substance use disorder, which usually begin around 15-19 years old [12]. The most common comorbidity of TS is ADHD, ranging from $60-80 \%$; the second common comorbidity is OCD, ranging from $11-80 \%$, other comorbidities are rage attacks (25-75\%), depression (13-76\%), sleep problems (12-62\%), migraine (25\%), and learning disabilities (23\%) [13]. High frequencies of comorbidities of TS indicate its clinical heterogeneity, as well as heterogeneity and complexity of the underlying etiologies, pathogenic pathways and neural networks.

\subsection{Prevalence of $T S$}

Several systematic reviews, in a total of 44 population studies from Europe, East Asia, Middle East, Far East, Oceania and North America, have reported that TS prevalence is between $0.3 \%$ and $0.9 \%$ in children [17-19]. TS has been reported in different cultures across different populations worldwide with similar phenomenology, but with lower prevalence in the Afro-Americans in the USA and the sub-Saharan Black Africans [17]. There were fewer studies on the prevalence of TS in adults. The prevalence of TS in adults was estimated between $0.05 \%$ and $0.1 \%[19,20]$. In general, tic disorders are less common in adults than children, which is consistent with partial or complete remission of tic symptoms during and after adolescence. In addition, studies have also shown that TS prevalence is higher in males than females. Male/female ratio is about 3-4:1 [19,21]. The latest study involving 122,884 Canadians suggested that prevalence of TS is $0.33 \%$ and $0.07 \%$ in youth (12-17 years old) and adults ( $>18$ years old), respectively; and the sex ratio is reported to be 5.31:1 in youth, and 1.93:1 in adults in this study [22]. Schlander et al. also described that the difference of TS prevalence between males and females decreased in adults [23]. Therefore, TS is a typical neurodevelopmental disorder, which is also influenced by sex difference during brain development.

\subsection{Heritability of TS}

Family studies have shown that the rate of TS in first-degree relatives of TS patients is 10-to-100-fold higher than general population [24]. The similar results (7- to 22-fold increase) were found in first-degree relatives of patients with chronic tic disorders (CTDs) [24]. In family studies, the heritability of tic disorders was estimated to be between 0.25 and $0.77[20,25]$. The results from the latest family study, which included 4826 individuals with TS or CTDs, suggested that the rate of TS or 
CTD in first-degree relatives was higher (odds ratio, OR: 18.69) than in second-degree relatives (OR: 4.58 ) and third-degree relatives (OR: 3.07), when compared with unrelated controls (matched on a 1:10 ratio) [25].

There were also family studies regarding the co-heritability of TS and its comorbidities. In a study of 222 affected sibling-pair (ASP) families collected by the Tourette's Syndrome Association International Consortium on Genetics (TSAICG), TS, OCD, ADHD, and ADHD + OCD were all found highly heritable in this TS-enriched family cohort; and a significant familial correlation was found between TS and OCD, and between OCD and ADHD. However, there was no significant familial correlation between TS and ADHD; whereas they seemed to share significant environmental correlation [26]. Another study of TS and ADHD, not OCD, suggested that TS and ADHD may still have some overlapped genetic factors [27].

Although initially some single large pedigrees of TS suggested autosomal dominant inheritance [28-32], further complex segregation analysis and principal component analysis in extended large pedigrees ascertained through TS probands indicated that the pattern of TS and other related tic disorders was not consistent with simple Mendelian inheritance, even after modelling explanatory variables, such as obsessive compulsive symptomatology [33]. Notably, there seem to be significant phenotypic variability within pedigrees in terms of severity and comorbidity [34].

Twin studies are important and valuable approach to delineate the genetic contribution to genetic disorder like TS. Price and his collages studied 43 pairs of same-sex twins, including 30 pairs of monozygotic (MZ) and 13 pairs of dizygotic (DZ) in 1985 [35]. Concordances rates for TS were 53\% for MZ and $8 \%$ for DZ. For tics, concordance rates were up to $77 \%$ and $23 \%$ for MZ and DZ pairs, respectively. The subsequent study on 16 pairs of MZ twins showed the concordance rate were $56 \%$ for TS and $94 \%$ for tic disorders [36]. In 2007, Bolton et al. investigated a community sample involving 46626 years old twin pairs using a two-phase design. The heritability was estimated at 0.50 for tic disorders; and by assessing 854 pairs at the second phase, concordance rate for tic disorders was 0.64 for MZ pairs and 0.33 for DZ pairs [37]. Another study screened a cohort of Swedish 9 and 12 years old for multi-psychiatric diseases, including tic disorders, autism spectrum disorders (ASD), ADHD, OCD etc. [38]; a total of 17,220 twins were recruited. The results suggested that genetic correlations accounted 0.56 of heritability (95\% CI: 0.37-0.68), with concordance rate of 0.38 for MZ pairs and 0.11 for DZ pairs for tic disorder. The same study also estimated the heritability by sex, i.e., 0.26 in girls and 0.39 in boys [38]. The tic heritability of adult twins was estimated at 0.33 in another study by Pinto et al. in 2016 [39].

Both family and twin studies have shown that the etiology of TS is at least partially of genetic origin; however, the inheritance is more likely to be complex than simple Mendeian mode. In general, TS and associated comorbidities have much lower heritability compared to other neuropsychiatric disorders, such as ASD (heritability: 0.80), schizophrenia (SCZ) (heritability: 0.81) and bipolar disorder (BPD) (heritability: 0.75) [40]., indicating other factors during development and from the environmental also play some roles in pathogenesis of TS and its comorbidities [37-39].

\section{Genome-Wide Linkage Studies of TS}

Due to the autosomal dominant-like inheritance pattern in some large extended pedigrees with TS and comorbidities, earlier stage of genetic research of TS had focused on genome-wide linkage studies (GWLSs) of TS families, which assess the probability in a given pedigree or pedigrees, where the disease and the genetic marker(s) are cosegregating. Several chromosomal regions were reported as potential candidate loci for TS through GWLSs, including chromosome 3p21-p14 [41], 4q34-q35 [42,43], 5q35.2-q35.3 [43], 6p21 [44], 7q31 [45-47], 11q23-24 [48-50], 13q31.1 [51], 15q21.1-15q21.3 [52], and $17 q 25[43,53]$. However, despite the earlier excitement and optimism about gene discovery for TS through GWLS approach, and some chromosomal regions have been implicated in some TS families, no gene or causal mutation of major effect has been discovered for the above-mentioned TS loci, except for the SLITRK1 locus on chromosome 13 [51] and the HDC locus on chromosome 15 [52]. The reasons behind these earlier disappointing gene discovery endeavors through GWLSs may be multiplicative, including phenotypic complexity, such as clinical and genetic heterogeneity of TS and its associated 
comorbidities, limited sample size, as well as limitation of the previous genetic technologies and statistical methodologies, e.g., the low coverage and resolution of the microsatellite marker panels. Since linkage analysis is based on calculation of recombination events in limited number of generations, it is sensitive to misspecified genetic information, such as individual affection status, allele frequency, mode and parameters about inheritance. Nevertheless, limited significant statistical results of TS GWLSs strongly suggest that the underlying genetic architecture of TS and associated comorbidities is more complex than simple Mendelian inheritances.

\section{Candidate Gene Association Studies of TS}

After unsuccessful GWLS attempts in TS gene discovery, researchers had turned to direct candidate gene linkage and association studies to identify the potential genetic contribution of TS. Based on progresses in neuroimaging, postmortem, animal models and pharmacological studies, it has been hypothesized that the cortico-striatal-thalamo-cortical (CSTC) pathways may underlay the pathogenesis of TS and related symptomatology; and abnormalities of those neurotransmitters and their signal transmissions could lead to the dysfunction of CSTC neural network and subsequent clinical manifestation of TS. Multiple neurotransmitter systems have been implicated in CSTC pathways [54], including dopaminergic, serotonergic, glutamatergic, gamma-amino butyric acid-(GABAergic), histaminergic, and other neurotransmitters [55-57]. Furthermore, a neurotransmitter dysfunction may also cause change in other neurotransmitters due to interaction or self-regulation among them [57].

Compared to genetic linkage analysis, genetic association is when one or more genotypes within a population, i.e., unrelated cases and controls, co-occur with a phenotypic trait more often than would be expected by chance occurrence. In earlier stage of genetic research of TS, many studies have been carried out to test genetic linkage and associations between various neurotransmitters and TS. Table 1 is a summary of candidate gene linkage and association studies of TS. In general, none candidate gene showed positive linkage result. Some association studies of TS showed positive results; however, their effects in TS seemed to be very small; and very often results were non-replicable; sometimes even controversial. As shown in Table 1, most studies were limited by sample sizes, therefore under power according to current standards. Interestingly, since 2005, majority of genetic association studies have achieved positive results, accounting for bigger sample size, more advanced technical methods and selected genes. 
Table 1. Main findings of linkage and association studies of neurotransmitter genes in Tourette's Syndrome (TS).

\begin{tabular}{|c|c|c|c|c|}
\hline Gene & Chromosome & Finding & Sample Size (Ethnicity) & Reference \\
\hline \multicolumn{5}{|l|}{ Dopaminergic } \\
\hline \multirow{4}{*}{ DRD1 (Dopamine receptor D1) } & \multirow{4}{*}{$5 q 34-35$} & \multirow{4}{*}{$\begin{array}{l}\text { No association was found between DRD1 and TS in both } \\
\text { family study and case-controls studies. (LOD }<-2 \text { ) }\end{array}$} & One pedigree, 85 interviewed in 116 members (NA*) & [58] \\
\hline & & & One large pedigree (Mennonite) & [59] \\
\hline & & & 50 TS, 35 TS + ADHD, 30 TS + OCD, 50 controls (NA) & {$[60]$} \\
\hline & & & 148 TS and 83 controls (Taiwanese) & [61] \\
\hline \multirow{9}{*}{ DRD2 (Dopamine receptor D2) } & \multirow{9}{*}{$11 \mathrm{q} 22-23$} & \multirow{4}{*}{$\begin{array}{l}\text { DRD2 (TaqIA) was associated with tic severity and } \\
\text { overlapped with other psychiatric disorders; multiple } \\
\text { SNPs of DRD2 ((H313H) C) were associated with TS. } \\
(p=0.001-0.03)\end{array}$} & 147 TS and 314 controls (Non-Hispanic Caucasian) & [62] \\
\hline & & & 225 TS and 67 controls (European) & [63] \\
\hline & & & 151 TS and 183 controls (Taiwanese) & [64] \\
\hline & & & 151 TS and 183 controls (Taiwanese) & [64] \\
\hline & & \multirow{5}{*}{$\begin{array}{l}\text { However, other studies showed that DRD2 (TaqIA) had } \\
\text { no association or linkage with tic severity and TS. }\end{array}$} & 124 Canadian and 48 Oregon (Canadian; Oregon) & [65] \\
\hline & & & $\begin{array}{l}4 \text { families (17 individuals using a derivative of YGTSS; } \\
47 \text { using the TS symptomatology evaluation) } \\
\text { (North American) }\end{array}$ & [66] \\
\hline & & & One pedigree, 85 interviewed in 116 members (NA) & [58] \\
\hline & & & 110 trios (French Canadian) & [47] \\
\hline & & & 61 TS and 109 parents (Germany) & [67] \\
\hline \multirow{4}{*}{ DRD3 (Dopamine receptor D3) } & \multirow{4}{*}{$3 q 13.3$} & \multirow{4}{*}{$\begin{array}{l}\text { Both family and case-control studies did not find } \\
\text { association between DRD3 (Mscl, rs6280) and TS. }\end{array}$} & 465 parent-child trios (NA) & [68] \\
\hline & & & One pedigree, 85 interviewed in 116 members (NA) & [58] \\
\hline & & & 110 trios (French Canadian) & [47] \\
\hline & & & 160 TS and 90 controls (Chinese) & [69] \\
\hline \multirow{7}{*}{ DRD4 (Dopamine receptor D4) } & \multirow{7}{*}{$11 \mathrm{p} 15.5$} & \multirow{3}{*}{$\begin{array}{l}\text { The higher number of DRD4 } 48 \mathrm{bp} \text { VNTR was found to be } \\
\text { associated with both TS and OCD. ( } p=0.004-0.03)\end{array}$} & 64 family trios (Canadian, Michigan, Oregon) & [70] \\
\hline & & & 61 OCD with and without tic (Mexican) & [71] \\
\hline & & & 110 trios (French Canadian) & [47] \\
\hline & & \multirow{4}{*}{ No association was found between $48 \mathrm{bp}$ VNTR and TS. } & 103 trios and 284 controls (European (Hungarian)) & [72] \\
\hline & & & 5 families (NA) & [73] \\
\hline & & & 102 trios (NA) & [74] \\
\hline & & & 266 TS and 236 controls (European (white, non-Hispanic)) & [75] \\
\hline
\end{tabular}


Table 1. Cont

\begin{tabular}{|c|c|c|c|c|}
\hline Gene & Chromosome & Finding & Sample Size (Ethnicity) & Reference \\
\hline \multirow{2}{*}{ DRD5 (Dopamine receptor D5) } & \multirow{2}{*}{$4 \mathrm{p} 16$} & \multirow{2}{*}{$\begin{array}{l}\text { Family studies did not find linkage between DRD5 and } \\
\text { TS. (LOD }<-4)\end{array}$} & One pedigree, 85 interviewed in 116 members (NA) & [58] \\
\hline & & & 106 individuals from 5 families (Canadian) & [76] \\
\hline \multirow{2}{*}{ TH (Tyrosine hydroxylase) } & \multirow{2}{*}{$11 \mathrm{p} 15.5$} & \multirow{2}{*}{$\begin{array}{l}\text { Family studies did not find linkage between TH (STR) } \\
\text { and TS. (LOD <-7) }\end{array}$} & One pedigree, 85 interviewed in 116 members (NA) & [58] \\
\hline & & & 5 families (NA) & [73] \\
\hline \multirow{7}{*}{ DAT1 (Dopamine transporter) } & \multirow{7}{*}{$5 \mathrm{p} 15.32$} & \multirow{3}{*}{$\begin{array}{l}\text { DAT1 } 40 \text { bp VNTR was associated with both tic severity } \\
\text { and tics; whereas DdeI polymorphism was only associated } \\
\text { with TS. }\end{array}$} & 103 trios and 284 controls (European (Hungarian)) & [72] \\
\hline & & & 225 TS and 67 controls (European) & [63] \\
\hline & & & 266 TS and 236 controls (European (white, non-Hispanic)) & [75] \\
\hline & & \multirow{4}{*}{$\begin{array}{l}\text { However, some studies showed there was no linkage } \\
\text { between } 40 \mathrm{bp} \text { VNTR and TS, although there was a trend } \\
\text { of excess transmission of allele } 10 \text { of VNTR. }\end{array}$} & 266 TS and 236 controls (European (white, non-Hispanic)) & [75] \\
\hline & & & 110 trios (French Canadian) & [47] \\
\hline & & & Four extend families (Canadian, Oregon) & [77] \\
\hline & & & 465 parent-child trios (NA) & [68] \\
\hline \multirow{4}{*}{ DBH (Dopamine $\beta$-hydroxylase) } & \multirow{4}{*}{$9 \mathrm{q} 34.3$} & Taq B1 allele was associated with TS. $(p=0.012)$ & 352 TS and 148 controls (Non-Hispanic Caucasian) & [63] \\
\hline & & \multirow{3}{*}{$\begin{array}{l}\text { Multiple markers of DBH (TaqI, } 19 \mathrm{bp} \text { ins/del, (CA)n) } \\
\text { have no association or linkage with TS. }\end{array}$} & One pedigree, 85 interviewed in 116 members (NA) & [58] \\
\hline & & & $\begin{array}{l}71 \text { nuclear families and } 5 \text { large-multigenerational families } \\
\text { (Canadian, Turkish) }\end{array}$ & [78] \\
\hline & & & 266 TS and 236 controls (European (white, non-Hispanic)) & [75] \\
\hline \multirow{3}{*}{$\begin{array}{l}\text { COMT } \\
\text { (Catechol-O-methyltransferase) }\end{array}$} & \multirow{3}{*}{ 22q11.2 } & \multirow{3}{*}{ No association between COMT Val158Met and TS. } & 103 trios and 284 controls (Caucasian) & [72] \\
\hline & & & 52 TS and 63 controls (Italian) & [79] \\
\hline & & & 465 parent-child trios (NA) & [68] \\
\hline \multicolumn{5}{|l|}{ Serotonergic } \\
\hline \multirow{3}{*}{ HTR1A (Serotonin receptor 1A) } & \multirow{3}{*}{$5 q 11.2-13$} & Two missenses were found in two TS patients. & 56 TS and 20 controls (Toronto) & [80] \\
\hline & & \multirow{2}{*}{$\begin{array}{l}\text { No association was found between Ile-28-Val substitution } \\
\text { and TS. }\end{array}$} & A large pedigree (British) & [58] \\
\hline & & & 92 TS and 210 controls (Germany) & [81] \\
\hline HTR2A (Serotonin receptor 2A) & 13q14-21 & $\begin{array}{l}\text { HTR2A } 102 \text { T/C was associated with Chinese TS. } \\
(p=0.02)\end{array}$ & 157 trios and 120 controls (Chinese) & [82] \\
\hline \multirow[t]{2}{*}{ HTR2C (Serotonin receptor 2C) } & \multirow[t]{2}{*}{$\mathrm{Xq} 22-23$} & $\begin{array}{l}\text { Both rs3813929 and rs518147 polymorphisms were } \\
\text { associated with TS. ( } p=0.01 \text { and } 0.02 \text {, respectively) }\end{array}$ & $87 \mathrm{TS}$ and 311 controls (European) & [83] \\
\hline & & No association was found between HTR2C and TS & 465 parent-child trios (NA) & {$[68]$} \\
\hline 5-HT3A, 3B (Serotonin receptor 3A, 3B) & $11 \mathrm{q} 23.2$ & $\begin{array}{l}\text { No association was found between 5-HT3 (Exon1, 3, 6, 7, } 9 \\
\text { at 5-HT3A; Exon5, 6; Intron 4, } 6 \text { at 5-HT3B) and TS. } \\
(p=0.058-0.098)\end{array}$ & 49 TS and controls (Germany) & [84] \\
\hline
\end{tabular}


Table 1. Cont.

\begin{tabular}{|c|c|c|c|c|}
\hline Gene & Chromosome & Finding & Sample Size (Ethnicity) & Reference \\
\hline 5-HT7 (Serotonin receptor 7) & 10q23 & $\begin{array}{l}\text { No genomewide significant linkage was found. } \\
\text { (LOD = 2.23) }\end{array}$ & Single extended pedigree (NA) & [85] \\
\hline \multirow{2}{*}{$\begin{array}{l}\text { SERT (SLC6A4) (5-HT transporter } \\
\text { (Solute carrier family } 6 \text { members 4)) }\end{array}$} & \multirow[t]{2}{*}{ 17q11.2 } & $\begin{array}{l}\text { Common and rare alleles of SLC6A4 were positively } \\
\text { associated with TS. }(p<0.01)\end{array}$ & 151 TS and 858 controls (European) & [86] \\
\hline & & No association was found. & 52 TS and 63 controls (Italian) & [79] \\
\hline \multirow{2}{*}{ TPH2 (Tryptphan hydroxylase 2) } & \multirow{2}{*}{$12 \mathrm{q} 21$} & $\begin{array}{l}\text { Positive results were found between TPH (SNP at intron } \\
\text { 2) and TS. }(p=0.002)\end{array}$ & 98 TS and 178 controls (Germany) & [87] \\
\hline & & No association was found. & 465 parent-child trios (NA) & [68] \\
\hline \multicolumn{5}{|l|}{ Glutamatergic } \\
\hline $\begin{array}{l}\text { EAAT1 (SLC1A3) (Solute carrier } \\
\text { family } 1 \text { (glial high affinity glutamate } \\
\text { transporter, member 3)) }\end{array}$ & $5 \mathrm{p} 13.2$ & $\begin{array}{l}\text { A missense (E219D) in EAAT1 was found associated with } \\
\text { TS patients. }(p=0.009)\end{array}$ & 256 TS and 224 controls (NA) & [88] \\
\hline $\begin{array}{l}\text { SAPAP3/DLGAP3 } \\
\text { (SAP90/PSD95-associated protein 3) }\end{array}$ & $1 \mathrm{p} 34.3$ & $\begin{array}{l}\text { Some SNPs was found to associated with TS. } \\
(p=0.013-0.026)\end{array}$ & $\begin{array}{l}289 \text { TS trios (USA, Canada, Great Britain and } \\
\text { the Netherlands) }\end{array}$ & [89] \\
\hline \multicolumn{5}{|l|}{ Histaminergic } \\
\hline \multirow{3}{*}{ HDC (Histidine decarboxylase) } & \multirow{3}{*}{$15 \mathrm{q} 21-22$} & \multirow{2}{*}{$\begin{array}{l}\text { Family studies showed that rare coding mutation was } \\
\text { associated with TS. }\end{array}$} & 520 TS families (European) & [90] \\
\hline & & & One large family (NA) & [52] \\
\hline & & No association was found. & 465 parent-child trios (NA) & [68] \\
\hline HRH3 (Histamine receptor H3) & 20 & No association was found. & 465 parent-child trios (NA) & [68] \\
\hline \multicolumn{5}{|l|}{ Adrenergic and other neurotransmitters } \\
\hline ADRA1C (Adrenergic receptor a1C) & 8p11.2 & $\begin{array}{l}\text { Adrenergic receptor 1C (PstI) showed no association with } \\
\text { TS. }\end{array}$ & 113 nuclear families (Canadian and Turkish) & [91] \\
\hline \multirow{2}{*}{ ADRA2A (Adrenergic receptor a2A) } & \multirow{2}{*}{$10 \mathrm{q} 24-26$} & \multirow{2}{*}{$\begin{array}{l}\text { Adrenergic receptor 2A (MspI, StyI, (CA)n) showed no } \\
\text { association with TS. }\end{array}$} & 113 nuclear families (Canadian and Turkish) & [91] \\
\hline & & & 160 TS and 83 controls (Taiwanese) & [92] \\
\hline ADORA1 (Adenosine A1 receptor) & $1 \mathrm{q} 32.1$ & $\begin{array}{l}\text { rs2228079 in exron2 was found associated with TS. } \\
(p=0.011)\end{array}$ & 162 TS and 210 controls (European (Polish)) & [93] \\
\hline $\begin{array}{l}\text { ADORA2A (Adenosine A2A } \\
\text { receptor) }\end{array}$ & 22q11.2 & $\begin{array}{l}\text { rs5751876 in exron3 was found associated with TS. } \\
(p=0.017)\end{array}$ & 162 TS and 210 controls (European (Polish)) & [93] \\
\hline \multirow{3}{*}{ MAO-A (Monoamine oxidase A) } & \multirow{3}{*}{ Xp11.3 } & VNTR in MAO-A was found associated with TS. $(p<0.05)$ & 110 trios (French Canadian) & [47] \\
\hline & & & $\begin{array}{l}229 \text { TS and } 90 \text { controls (European } \\
\text { (non-Hispanic Caucasians)) }\end{array}$ & [94] \\
\hline & & No association was found & 465 parent-child trios (NA) & [68] \\
\hline
\end{tabular}

NA: ethnicity information not available; LOD: logarithm of the odds (to the base of 10); SNPs: single nucleotide polymorphisms; YGTSS: Yale Global Tic Severity Scale; VNTR: variable number tandem repeat; ADHD: attention deficit hyperactivity disorder; OCD: obsessive-compulsive disorder. 


\section{Genome-Wide Association Studies of TS and Other Psychiatric Disorders}

Facilitated by the advent of SNP array technologies and statistical methodologies, as well as the collective efforts of large scale biobanks for research materials, genome-wide association study (GWAS) has become the main stream of genetic studies of common diseases in the past decade. The current GWAS Catalog contains 3055 publications and reports 39,360 unique SNP-trait associations in nearly 2000 traits or diseases [95]. Psychiatric disorders fall into the complex trait category; and most psychiatric disorders are common and highly heritable. Therefore, GWAS has been the focus of considerable effort in field of psychiatric genetics in the past decade. To date, over 400 GWAS studies have been published in psychiatric disorders like SCZ (104 GWAS analyses) [95-97], ASD (23 GWAS analyses) [95,98,99], BPD (85 GWAS analyses) [95,100,101], MDD (major depressive disorder) (55 GWAS analyses) [95,102,103], OCD (5 GWAS analyses) [95,104,105] and ADHD (33 GWAS analyses) [95,106,107]. These research results have markedly increased our understanding and knowledge of the genetic basis of these psychiatric disorders, and have yielded empirical data on genetic architecture and pathways critical to address the long-standing debates in the field of psychiatry. Table 2 shows a summary of GWASs of several main psychiatric disorders. In general, the effects of risk variants from GWASs are small but wide-spread genome-wide; and the majority of GWAS-identified variants fall in noncoding regions of the human genome. However, further annotations indicate that these regions are enriched for active elements for gene expression regulation in relevant cell functions $[108,109]$.

So far, only two GWASs of TS and one replication study have been published to date; one reached a marginal genomewide significance and the other GWAS failed to identify genome-wide significant loci for TS [110-112]. These results may have a close relationship with the sample size (1285 cases / 4964 controls, and 2498 cases / 6277 controls, respectively for each TS GWAS), which were much smaller than other major psychiatric GWASs. To date, there are no significant finding in ADHD and OCD GWASs either, most likely due to limited sample sizes as well. Nevertheless GWASs of ADHD and OCD found some top signals within some interesting candidate genes, such as LMOD2, WASL, ASB15, and SHFM1 genes in ADHD GWASs [113,114]; and PTPRD [104] and FAIM2 [105] genes in OCD GWASs.

One unambiguous conclusion from all GWASs is that complex traits are polygenic; and multiple lines of evidence are consistent with widespread pleiotropy for complex traits; these features are particularly striking in GWASs of psychiatric disorders. Widespread but small effects indicate that these common risk variants are not the main cause of disease phenotype under study, but rather just reflect the minimal peripheral polymorphic effects of the underlying molecular networks in different individuals and populations; and in case of TS GWAS, the subtle functional diversity or polymorphisms of the CSTC network. 
Table 2. Genome-wide association studies (GWAS) findings in main psychiatric disorders.

\begin{tabular}{|c|c|c|c|c|c|c|c|c|c|c|}
\hline Diseases & $\begin{array}{l}\text { Case/Control } \\
\text { D: Discover; } \\
\text { R: Replication; } \\
\text { C: Combined }\end{array}$ & Ethnicity & Analysis & Results & No. of Loci & No. of Genes & Top Candidate Genes & $\begin{array}{l}\text { Top SNP } \\
\text { Chromosomal } \\
\text { Location }\end{array}$ & $\begin{array}{l}p \text {-Value of Top SNP; Odds } \\
\text { Ratio with } \\
\text { Confidence Interval }\end{array}$ & Reference \\
\hline sCZ & $\begin{array}{l}\text { D:34,241/45,604/1235 } \\
\text { trios } \\
\text { R: } 1513 / 66,236 \\
\text { C: } 36,989 / 113,075\end{array}$ & $\begin{array}{l}\text { European/East } \\
\text { Asian }\end{array}$ & Meta-analysis & $\begin{array}{l}128 \text { independent } \\
\text { associations spanning } 108 \\
\text { conservatively defined loci } \\
\text { that meet genome-wide } \\
\text { significance }\left(p \leq 5 \times 10^{-8} 8 \text {, }\right. \\
83 \text { of which have not been } \\
\text { previously reported. }\end{array}$ & 108 & 348 & $\begin{array}{l}\text { MHC region, DRD2, GRM3, } \\
\text { GRIN2A, SRR, GRIA1, } \\
\text { CACNA1C, CACNB2, } \\
\text { CACNA1I }\end{array}$ & rs115329265; 6p22.1 & $\begin{array}{l}3.48 \times 10^{-31} ; \text { OR: } 1.205 \\
(55 \% \text { CI: } 1.168-1.244)\end{array}$ & [96] \\
\hline BPD & $\begin{array}{l}\text { D: } 7647 / 27,303 \\
\text { R: } 2137 / 3168 \\
\text { C: } 9784 / 30,471\end{array}$ & European & Meta-analysis & $\begin{array}{l}\text { Six autosomal loci exceeded } \\
\text { genome-wide significance. }\end{array}$ & 6 & 7 & $\begin{array}{l}\text { ERBB2, ELAVL2, MAD1L1, } \\
\text { TRANK1, MIR2113, POU3F2, } \\
\text { DDN }\end{array}$ & rs9834970; 3p22.2 & $\begin{array}{l}4.83 \times 10^{-10} ; \text { OR: } 0.88 \\
(95 \% \text { CI: } 0.85-0.92)\end{array}$ & [115] \\
\hline ASD & $\begin{array}{l}\text { D: } 7387 / 8567 \\
\text { R: } 9152 / 148,667 \\
\text { C: } 16,539 / 157,234\end{array}$ & European & Meta-analysis & $\begin{array}{l}\text { None of the markers } \\
\text { investigated exceeded } \\
\text { genomewide threshold in } \\
\text { the discovery cohort; } \\
\text { meta-analyzed against the } \\
\text { Danish iPSYCH data a } \\
\text { single GWSA; } \\
\text { cross-disorder ASD and } \\
\text { schizophrenia } \\
\text { meta-analyses identified } \\
12 \text { GWS loci not previously } \\
\text { identified as GWS in the } \\
\text { PGC schizophrenia GWAS. }\end{array}$ & 1 & 13 & $\begin{array}{l}\text { C10orf76, CUEDC2, ELOVL3, } \\
\text { FBXL15, GBF1, HPS6, LDB1, } \\
\text { MIR 1466, NFK2B, NOLC1, } \\
\text { PITX3, PPRC1, PSD }\end{array}$ & $\begin{array}{l}\text { rs1409313 } \\
\text { (meta-analyzed } \\
\text { against the Danish } \\
\text { iPSYCH data a single } \\
\text { GWAS association); } \\
\text { 10q24.32 }\end{array}$ & $\begin{array}{l}1.058 \times 10^{-8} ; \text { OR: } 1.12 \\
(95 \% \text { CI: } 1.08-1.16)\end{array}$ & [117] \\
\hline Cross-disorder & $\begin{array}{l}\text { D: } 6990 \text { BPD, } 9227 \\
\text { MDD, } 9379 \text { SCZ, } 161 \\
\text { ASD, } 4788 \text { ASD trios, } \\
\text { 840 ADHD, } 1947 \\
\text { ADHD trios } / 27,888 \\
\text { R: NA } \\
\text { C: } 33,332 / 27,888\end{array}$ & European & $\begin{array}{l}\text { Cross-disorder } \\
\text { analysis }\end{array}$ & $\begin{array}{l}\text { SNPs at four loci surpassed } \\
\text { the cutoff for genome-wide } \\
\text { significance }\left(p \leq 5 \times 10^{-8}\right) \\
\text { in the primary analysis: } \\
\text { regions on chromosomes } \\
\text { 3p21 and 10q24, and SNPs } \\
\text { within two L-type } \\
\text { voltage-gated calcium } \\
\text { channel subunits, } \\
\text { CACNA1C and CACNB2. }\end{array}$ & 4 & $4+$ & $\begin{array}{l}\text { ITIH3, AS3MT, CACNA1C, } \\
\text { CACNB2 }\end{array}$ & rs2535629; 3p21.1 & $\begin{array}{l}2.54 \times 10^{-12} ; \text { OR: } 1 \times 10 \\
(95 \% \text { CI: 1.07-1.12) }\end{array}$ & [118] \\
\hline \multirow[t]{2}{*}{ TS } & $\begin{array}{l}\text { D: } 1285 / 4964 \\
\text { R: } 211 / 285 \\
\text { C: } 1496 / 5249\end{array}$ & $\begin{array}{l}\text { European/Ashkenazi } \\
\text { Jews/French } \\
\text { Canadians/Latin } \\
\text { American }\end{array}$ & Meta-analysis & $\begin{array}{l}\text { One marker achieved a } \\
\text { genome-wide threshold of } \\
\text { significance }\left(p \leq 5 \times 10^{-8}\right) \text {. }\end{array}$ & 1 & 1 & COL27A1 & rs7868992; 9q32 & $2.94 \times 10^{-8}$ & [110] \\
\hline & $\begin{array}{l}\text { D: } 609 / 610 \\
\text { R: } 1285 / 4964 \\
\text { C: } 1894 / 5574\end{array}$ & $\begin{array}{l}\text { European, Hungary, } \\
\text { Germany, Austria, } \\
\text { Italy, Greece, French } \\
\text { Canadian }\end{array}$ & Meta-analysis & $\begin{array}{l}\text { No markers achieved a } \\
\text { genome-wide threshold of } \\
\text { significance }\left(p \leq 5 \times 10^{-8}\right) \text {. }\end{array}$ & 0 & 0 & NTN4 & rs2060546; 12q22 & $5.80 \times 10^{-7}$ & [111] \\
\hline
\end{tabular}


Table 2. Cont.

\begin{tabular}{|c|c|c|c|c|c|c|c|c|c|c|}
\hline Diseases & $\begin{array}{l}\text { Case/Control } \\
\text { D: Discover; } \\
\text { R: Replication; } \\
\text { C: Combined }\end{array}$ & Ethnicity & Analysis & Results & No. of Loci & No. of Genes & Top Candidate Genes & $\begin{array}{l}\text { Top SNP } \\
\text { Chromosomal } \\
\text { Location }\end{array}$ & $\begin{array}{l}p \text {-Value of Top SNP; Odds } \\
\text { Ratio with } \\
\text { Confidence Interval }\end{array}$ & Reference \\
\hline & $\begin{array}{l}\text { D: } 1310 \text { OCD, } 834 \text { TS, } \\
579 \text { TS + } \\
\text { OCD /5667/290 OCD } \\
\text { trios } \\
\text { R: NA } \\
\text { C: } 2763 / 5667 / 290 \text { trios }\end{array}$ & $\begin{array}{l}\text { European, South } \\
\text { African Afrikaner, } \\
\text { Ashkenazi Jewish }\end{array}$ & $\begin{array}{l}\text { Cross-disorder } \\
\text { analysis }\end{array}$ & $\begin{array}{l}\text { No individual } \\
\text { single-nucleotide } \\
\text { polymorphisms (SNPs) } \\
\text { achieved genome-wide } \\
\text { significance; the GWAS } \\
\text { signals were enriched for } \\
\text { SNSs strongly associated } \\
\text { with variations in brain } \\
\text { gene expression levels } \\
\text { (expression quantitative } \\
\text { loci, or eQTLS); } \\
\text { No significant polygenic } \\
\text { signal was detected across } \\
\text { the two disorders. }\end{array}$ & 0 & 0 & POU1F1, CHMP2B, MIR4795 & rs4988462; 3p11 & $3.70 \times 10^{-7}$ & [112] \\
\hline \multirow[t]{2}{*}{ OCD } & $\begin{array}{l}\text { D: } 1406 \text { OCD, } 1489 \\
\text { controls from } 1065 \\
\text { families; } 192 / 1984 \\
\text { R: NA } \\
\text { C: } 1598 / 3474 \\
\end{array}$ & NR (U.S.) & Discovered-analysis & $\begin{array}{l}\text { Identified interesting } \\
\text { candidate genes for } \mathrm{OCD} \text {, } \\
\text { but failed to detect any } \\
\text { genome-wide } \\
\text { significant finding. }\end{array}$ & 0 & 0 & $\begin{array}{l}\text { PTPRD, NEUROD6, SV2A, } \\
\text { GRIA4, SLC1A2 }\end{array}$ & rs4401971; $9 \mathrm{p} 23$ & $4.13 \times 10^{-7}$ & [104] \\
\hline & $\begin{array}{l}\text { D: } 1465 / 5557 / 400 \text { trios } \\
\text { R: NA } \\
\text { C: } 1465 / 5557 / 400 \text { trios }\end{array}$ & $\begin{array}{l}\text { European, NR, } \\
\text { Hispanic or Latin } \\
\text { American (U.S., } \\
\text { United AArab } \\
\text { Emirates, Brazil, } \\
\text { Italy, Netherlands, } \\
\text { Canda, South } \\
\text { Africa, Germany, } \\
\text { Costa Rica, France, } \\
\text { Mexico) }\end{array}$ & Meta-analysis & $\begin{array}{l}\text { No SNP was identified to } \\
\text { be associated with OCD at } \\
\text { a genome-wide significant } \\
\text { level in the combined } \\
\text { trio-case-control sample; } \\
\text { enrichment of methylation } \\
\text { QTLs }(p<0.001) \text { and } \\
\text { frontal lobe expression } \\
\text { quantitative trait loci } \\
\text { (eQTLs) }(p=0.001) \text { was } \\
\text { observed within the } \\
\text { top-ranked SNPs }(p<0.01) \\
\text { from the trio case-control } \\
\text { analysis. }\end{array}$ & 0 & 0 & FAIM2 & rs297941; 12q13.12 & $4.13 \times 10^{-7}$ & [105] \\
\hline \multirow[t]{2}{*}{ ADHD } & $\begin{array}{l}\text { D: } 17,666 \text { children } \\
\text { R: NA } \\
\text { C: } 17,666 \text { children }\end{array}$ & $\begin{array}{l}\text { NR (U.S., Australia, } \\
\text { NR) }\end{array}$ & Meta-analysis & $\begin{array}{l}\text { Meta-analysis did not } \\
\text { detect genome-wide } \\
\text { significant SNPs, but three } \\
\text { genes showed a gene-wide } \\
\text { significant association } \\
(p \text { values between } 1.46 \times \\
\left.10^{-6} \text { and } 2.66 \times 10^{-6}\right) ; \\
\text { SNP-based heritability } \\
\text { ranged from } 5 \% \text { to } 34 \% \text {. }\end{array}$ & 0 & 0 & LMOD2, WASL, ASB15 & $\begin{array}{l}\text { rs56159542 } \\
19 p 13.11\end{array}$ & $1.48 \times 10^{-7}$ & [113] \\
\hline & $\begin{array}{l}\text { D: } 896 / 2455 / 2064 \text { trios } \\
\text { R: NA } \\
\text { C: } 896 / 2455 / 2064 \text { trios }\end{array}$ & European & Meta-analysis & $\begin{array}{l}\text { No genome-wide } \\
\text { significant association } \\
\left(p \leq 5 \times 10^{-8}\right) \text { was found. }\end{array}$ & 0 & 0 & SHFM1 & $\begin{array}{l}\text { rs1464807 } \\
7 \mathrm{q} 21.3\end{array}$ & $1.1 \times 10^{-6}$ & [114] \\
\hline
\end{tabular}

D: Discovery, R: Replication, C: Combined; NR: ethnicity not reported; OR: odds ratio; SCZ: schizophrenia; BPD: bipolar disorder; MDD: major depression; ASD: autism spectrum disorder; ADHD: attention-deficit hyperactivity disorder; GWAS: genomewide association study. 


\section{Chromosomal Abnormalities and Copy Number Variants (CNVs) of TS}

Chromosomal aberrations studies are an important aspect of TS genetics with more significant findings. By single or combined in situ hybridization, chromosomal microarray, cytogenetic and next-generation sequencing, chromosomal aberrations studies have identified several large, rare structural aberrations associated with TS and related phenotypes. Table 3 is a summary of some main candidate loci and genetic findings. Among the most interesting candidate genes, Slit and Trk-like, family member 1 (SLITRK1) gene on 13q31.1, discovered in a TS patient with a de novo inversion [51]. SLITRK1 is a transmembrane protein that regulates neurite outgrowth by phosphorylation-dependent manner; and it has been shown to control neurite outgrowth; and it is expressed in the embryonic and postnatal brain, including the cortex, thalamus, and basal ganglia, which correlate with the neuroanatomical regions most commonly implicated in TS [119-121]. Inner mitochondrial membrane protein $2 L$ (IMMP2L) gene on $7 \mathrm{q} 22-\mathrm{q} 31$ is also an interesting candidate gene for TS, disrupted by a breakpoint in 7q31 in TS patients, as well as implicated in autism and speech-language disorders $[45,46,122,123]$. IMMP2L encodes the inner membrane peptidase subunit 2, a mitochondrial protease involved in cleaving the space-sorting signals of mitochondrial membrane proteins; and defective IMMP2L may lead to disrupted mitochondria function [123]. Mitochondrial dysfunction has been associated with a range of human disorders, including neuropsychiatric disorders [123]. Disruptions of Contactin associated protein-like 2 gene (CNTNAP2) on 7q35-q36 [124,125] and Neuroligin 4 (NLGN4) on Xp22.3 [126] have also been reported to be associated with TS and other neurodevelopmental disorders. 
Table 3. Genomic structural aberrations in TS.

\begin{tabular}{|c|c|c|c|c|c|c|}
\hline Cytoband & Variation Type & Karyotype & Carrier Frequency and Phenotype & Candidate Region & Candidate Gene & Reference \\
\hline $6 q 16$ & $\begin{array}{l}\text { Translocation and } \\
\text { deletion }\end{array}$ & 46, XY, balanced $\mathrm{t}(6 ; 22)(\mathrm{q} 16.2 ; \mathrm{p} 13)$ & $\begin{array}{l}\text { One family, } 2 \text { carriers of translocation + } \\
\text { deletion: proband with TS + OCD; mother } \\
\text { with OCD }\end{array}$ & $\begin{array}{l}\text { A } 400 \mathrm{~kb} \text { deletion, } 1.3 \mathrm{Mb} \text { telomeric to the } \\
\text { translocation breakpoint, was also identified } \\
\text { on } 6 \mathrm{q} 16 .\end{array}$ & $\begin{array}{l}\text { GPR63, NDUFA4, and } \\
\text { KLHL32 in the } 400 \mathrm{~kb} \\
\text { deletion on } 6 \mathrm{q} 16\end{array}$ & [127] \\
\hline \multirow[t]{4}{*}{$7 \mathrm{q} 22-\mathrm{q} 31$} & Translocation & $46, \mathrm{XY}, \mathrm{t}(7 ; 18)(\mathrm{q} 22 ; \mathrm{q} 22.3)$ & $\begin{array}{l}\text { One pedigree with } 12 \text { individuals; } 9 \text { carriers: } \\
4 \text { with vocal tics; } 1 \text { with motor tics; } 1 \text { with TS, } \\
3 \text { without TS }\end{array}$ & $\begin{array}{l}\text { Breakpoint at 7q22 was localized between } \\
\text { markers D75515 and D75522. }\end{array}$ & IMMP2L & [45] \\
\hline & Duplication/Insertion & $46, \mathrm{XY}, \operatorname{dup}(7)(\mathrm{q} 22.1-\mathrm{q} 31.1)$ & $\begin{array}{l}1 \text { patient with TS + depression + delayed } \\
\text { speech + mental retardation }\end{array}$ & $\begin{array}{l}\text { Breakpoint on chr7 was mapped to 7q22-q31, } \\
\text { between D7S515 and D7S552, } 6.5 \mathrm{~kb} \text {. }\end{array}$ & IMMP2L & {$[46,128]$} \\
\hline & $\begin{array}{l}\text { Translocation and } \\
\text { deletion }\end{array}$ & $\begin{array}{l}46, \mathrm{XY}, \\
\mathrm{t}(2 ; 7)(\mathrm{p} 24.2 ; \mathrm{q} 31) \operatorname{del}(7)(\mathrm{q} 31.1 \mathrm{q} 31.2)\end{array}$ & $\begin{array}{l}1 \text { TS patient with motor tics + } \\
\text { language impairment }\end{array}$ & $\begin{array}{l}\text { Translocation breakpoint on chr7 was mapped } \\
\text { to } 7 \mathrm{q} 31 \text {. A } 7.25 \mathrm{Mb} \text { deletion within introns } 2-3 \\
\text { on 7q31.1-31.2 was identified. }\end{array}$ & IMMP2L & [122] \\
\hline & Deletion & Intragenic deletion & $\begin{array}{l}188 \text { TS patients and } 316 \text { controls: } 7 \text { out of } 188 \\
\text { TS; } 3 \text { out of } 316 \text { controls carried the deletion } \\
(p=0.0047)\end{array}$ & $\begin{array}{l}\text { 49 331 kb deletions were identified at the } \\
\text { 5'end of IMMP2L gene. }\end{array}$ & IMMP2L & [123] \\
\hline \multirow[t]{2}{*}{$7 \mathrm{q} 35-\mathrm{q} 36$} & $\begin{array}{l}\text { Complex } \\
\text { chromosomal } \\
\text { insertion/translocation }\end{array}$ & $\begin{array}{l}\text { Father: 46, XY, inv(2)(p23q22), } \\
\text { ins(7;2)(q35q36;p21p23); Daughter and } \\
\text { son: } 46, X X / X Y, \\
\operatorname{der}(7) \text { ins(7;2)(q35q36;p21p23) }\end{array}$ & $\begin{array}{l}\text { One family with } 3 \text { carriers: daughter and son } \\
\text { with TS + OCD; father with OCD + depression }\end{array}$ & $\begin{array}{l}\text { a chromosome 2p21-p23 insertion on } \\
\text { chromosome 7q35-q36, interrupting the } \\
\text { contactin-associated protein } 2 \text { gene } \\
\text { (CNTNAP2). }\end{array}$ & CNTNAP2 & [124] \\
\hline & Translocation & $\begin{array}{l}\text { Proband and aunt: } 46, \mathrm{XY} / \mathrm{XX} \\
\operatorname{der}(7) \mathrm{t}(7 ; 15)(\mathrm{q} 35 ; \mathrm{q} 26.2)\end{array}$ & $\begin{array}{l}\text { One large family with } 5 \text { carriers: } 2 \text { (proband } \\
\text { and aunt) with multiple congenital } \\
\text { malformations, severe mental retardation and } \\
\text { did not have any language development, and } \\
\text { scoliosis. Father, grandmother, father of } \\
\text { grandmother: } 46, \text {, XY/XX, balanced } \\
\mathrm{t}(7 ; 15)(\mathrm{q} 35 ; \mathrm{q} 26.2) \text { without TS and } \\
\text { other malformations }\end{array}$ & $\begin{array}{l}\text { Breakpoint localized to a region of } \\
\text { approximately } 21 \text { kb within intron } 11 \text { of the } \\
\text { CNTNAP2 gene; and carriers without TS. }\end{array}$ & CNTNAP2 & [125] \\
\hline \multirow[t]{2}{*}{ 8q13-q22 } & Translocation & $46, X Y, t(6 ; 8)(\mathrm{p} 23 ; \mathrm{q} 13)$ & $\begin{array}{l}\text { One family with } 3 \text { carriers: proband with TS + } \\
\text { OCD + LD; half-sister with TS + OCD; mother } \\
\text { with LD + TS?; One family with } 1 \text { carrier: } \\
\text { with TS + ADHD }\end{array}$ & Breakpoint within 8q13. & Unknown & [129] \\
\hline & Translocation & $46, \mathrm{XY}, \mathrm{t}(1 ; 8)(\mathrm{q} 21.1 ; \mathrm{q} 22.1)$ & $\begin{array}{l}4 \text { carriers in one family, } 1 \text { without TS; } 1 \text { with } \\
\text { TS + ADHD + OCD, } 2 \text { with motor tics + } \\
\text { ADHD }\end{array}$ & Breakpoint within $8 \mathrm{q} 22$. & $\begin{array}{l}\text { CBFA2T1 located } 11 \mathrm{~kb} \text { distal } \\
\text { to the 8q breakpoint }\end{array}$ & [130] \\
\hline \multirow[t]{3}{*}{ 9p } & Deletion & $46, X Y, \operatorname{del}(9)(q \operatorname{qter}-\mathrm{p} 2304:)$ & One patient with TS + OCD + ADD & Breakpoint lies on chr9. & Unknown & [131] \\
\hline & Translocation & $46, \mathrm{XY}, \mathrm{t}(3 ; 9)(\mathrm{q} 25.1 ; \mathrm{q} 34.3)$ & 1/176 TS cases & $\begin{array}{l}\text { Breakpoint on chr9q34.4 within intron7 of } \\
\text { OLFM1 gene. }\end{array}$ & OLFM1 & [132] \\
\hline & Translocation & $46, \mathrm{XX} / \mathrm{XY}, \mathrm{t}(3 ; 9)(\mathrm{q} 25.1 ; \mathrm{q} 34.3)$ & One family with 2 carriers with TS & Unknown & Unknown & [132] \\
\hline \multirow[t]{2}{*}{$13 q$} & Var321, inversion & $46, X Y, \operatorname{inv}(13)(\mathrm{q} 31.1 ; \mathrm{q} 33.1)$ & $\begin{array}{l}\text { 1/174 TS patients: with TS+ADHD; } 2 \text { patients } \\
\text { carried var321 }\end{array}$ & Breakpoint spans the 13q31.1 and 13q33.1. & $\begin{array}{l}\text { SLITRK1, ERCC5 and } \\
\text { SLC10A2 }\end{array}$ & [51] \\
\hline & Var321, inversion & $46, X Y, \operatorname{inv}(13)(q 31.1 ; q 33.1)$ & $\begin{array}{l}\text { 2/174 TS patients carried var321, none of } 2148 \\
\text { controls carried var321 }(p=0.0056)\end{array}$ & Breakpoint spans the 13q31.1 and 13q33.1. & $\begin{array}{l}\text { SLITRK1, ERCC5 and } \\
\text { SLC10A2 }\end{array}$ & [133] \\
\hline 15q13.3; Xq21.31 & $\begin{array}{l}\text { Microduplication and } \\
\text { deletion }\end{array}$ & $\begin{array}{l}\text { Deletion in 15q13.2, duplication in } \\
\text { both } 15 \mathrm{q} 13.3 \text { and Xq21.31 }\end{array}$ & $\begin{array}{l}\text { One family with } 2 \text { carriers: proband with TS + } \\
\text { OCD + rage attack; mother with ADHD }\end{array}$ & $\begin{array}{l}\text { Breakpoint within } 15 \mathrm{q} 13.2,15 \mathrm{q} 13.3 \text { and } \\
\text { Xq21.31 (2-bp deletion at 15q13.2; } 433 \mathrm{~kb} \\
\text { duplication at 15q13.3; } 732 \mathrm{~kb} \text { duplication at } \\
\text { Xq21.31). }\end{array}$ & $\begin{array}{l}\text { CHRNA7, PABPC5 and } \\
\text { PCDH11X }\end{array}$ & [134] \\
\hline
\end{tabular}


Table 3. Cont

\begin{tabular}{|c|c|c|c|c|c|c|}
\hline Cytoband & Variation Type & Karyotype & Carrier Frequency and Phenotype & Candidate Region & Candidate Gene & Reference \\
\hline $15 q 13-q 22.3$ & Inversion & $46, X Y, \operatorname{inv}(15)(q 13 ; q 22.3)$ & $\begin{array}{l}\text { One family with } 1 \text { carrier: proband with } \\
\text { motor tics + ADHD + OCD + } \\
\text { development delay }\end{array}$ & Inversion spans 15q13-q22. & Unknown & [135] \\
\hline $16 \mathrm{q} 22-\mathrm{q} 23$ & Fragile sites & 46, XX/XY, fr(16)(q22-23) & $\begin{array}{l}\text { 3/281 carriers: one with TS + Huntington's } \\
\text { Disease; one with TS + BPD + ASD + MR; one } \\
\text { with TS + BPD + MR }\end{array}$ & Fragile site lies within 16q22-q23. & Unknown & [136] \\
\hline \multirow[t]{2}{*}{ 17p11 } & Translocation & $46, X Y, t(6 ; 17)(q 21 ; p 11)$ & $\begin{array}{l}\text { One family with } 2 \text { carriers: proband with TS; } \\
\text { son with TS + LD }\end{array}$ & Breakpoint lies within $17 \mathrm{p} 11$. & Unknown & [137] \\
\hline & Deletion & $46, \mathrm{XY}, \operatorname{del}(17)(\mathrm{p} 11.2)$ & $\begin{array}{l}\text { One patient with TS + SMS + SIB + } \\
\text { ADHD + OCB }\end{array}$ & & Unknown & [138] \\
\hline $18 \mathrm{q} 21.1-\mathrm{q} 22.3$ & Translocation & $46, \mathrm{XX}, \mathrm{t}(2 ; 18)(\mathrm{p} 12 ; \mathrm{q} 22)$ & One patient with OCD & Breakpoint lies within 18q. & CDH7 and CDH19 & [139] \\
\hline 18q21.1-q22.2 & Inversion & $46, X Y, \operatorname{inv}(18)(\mathrm{q} 21 ; \mathrm{q} 22)$ & One patient with tics + OCD & $\begin{array}{l}\text { Breakpoint lies at } 18 q \text {, the inverted } \\
\text { chromosome showing delayed } \\
\text { replication timing. }\end{array}$ & $\begin{array}{l}2 \text { transcripts, GTSCR-1 } \\
\text { and CIS4 }\end{array}$ & [140] \\
\hline 22q11 & Deletion & $46, \mathrm{XX}, \operatorname{del}(22)(\mathrm{q} 11)$ & $\begin{array}{l}\text { One family with } 2 \text { carriers: proband with TS + } \\
\text { ADHD + OCD + MR; mother with phonic tic }\end{array}$ & A deletion at 22q11. & Unknown & [141] \\
\hline $\mathrm{xp}_{\mathrm{p} 22.3}$ & Deletion & $46, X Y$ & $\begin{array}{l}\text { One family with } 3 \text { carriers: proband with TS + } \\
\text { ASD; brother with TS + ADHD, mother } \\
\text { without TS, but with depression + anxiety + } \\
\text { learning disability }\end{array}$ & $\begin{array}{l}\text { A small deletion encompassing exons 4, 5, } \\
\text { and } 6 \text { of NLGN4 at Xp22.3. }\end{array}$ & NLGN4 & [126] \\
\hline
\end{tabular}

LD: learning disorder; ADD: attention deficit disorder; MR: mental retardation; SMS: Smith-Magenis syndrome; SIB: self injurious behavior; OCB: obsessive compulsive behavior. 
$\mathrm{CNV}$ is a special type of structural variation, i.e., a type of duplication or deletion event that affects a considerable number of base pairs at the same chromosomal location [142]. CNVs have been identified as causal genetic variants in other psychiatric disorders [143,144]. It has been reported that de novo CNVs are strongly associated with ASD and SCZ [143-149]. In ASD, de novo CNV in simplex families is 5 times and 10 times higher than multiplex families and controls, respectively [145]. In SCZ, de novo CNV is 8 times higher in sporadic cases than in controls [148]. It has been estimated that increased large CNV and chromosomal rearrangement may contribute to $5-10 \%$ risk of ASD [149]. The other neurodevelopmental conditions, such as bipolar disorder, epilepsy, and intellectual deficiency also share a highly similar large CNV landscape with potential pathogenicity $[150,151]$.

Table 4 summarizes CNV studies in TS. Approximately $1 \%$ of TS cases carry one of these CNVs, indicating that rare structural variation contributes significantly to the genetic architecture of TS structural variants, as well as increased global CNV burden that is mainly driven by large, rare, clinically relevant events, contribute significantly to the genetic architecture of TS, in which larger CNVs could create imbalance for more genes during neurodevelopment and lead to more severe outcomes. 
Table 4. Copy number variations in TS.

\begin{tabular}{|c|c|c|c|c|c|c|c|c|c|c|c|}
\hline Reference & $\begin{array}{l}\text { Sample Size } \\
\text { Case/Controls }\end{array}$ & Ethnicity & $\begin{array}{l}\text { Genotyping } \\
\text { Technology }\end{array}$ & Targeted CNV & Genomewide Finding & $\begin{array}{l}\text { Candidate } \\
\text { Region }\end{array}$ & Type of CNV & Frequency & CNV Size & Candidate Gene & CNV Type \\
\hline \multirow{5}{*}{$\begin{array}{l}\text { Sundaram et al., } \\
2010[152]\end{array}$} & \multirow{5}{*}{$111 / 73$} & \multirow{5}{*}{ European American } & \multirow{5}{*}{$\begin{array}{l}\text { Genomewide SNP } \\
\text { chip genotyping }\end{array}$} & \multirow{5}{*}{$\begin{array}{l}\text { Recurrent or de } \\
\text { novo rare exonic } \\
\text { CNVs }\end{array}$} & \multirow{5}{*}{5 rare $\mathrm{CNV}$ s were found in 10 out of 111 patients with $\mathrm{TS}$. } & $3 q 25.1$ & Deletion & $\begin{array}{l}\begin{array}{l}3 / 111 \text { in cases, } 0 / 73 \\
\text { in controls }\end{array} \\
\text { int }\end{array}$ & $30-40 \mathrm{~kb}$ & AADAC & Recurrent \\
\hline & & & & & & $2 \mathrm{p} 16$ & Deletion & $\begin{array}{l}2 / 111 \text { in cases, } 0 / 73 \\
\text { in controls }\end{array}$ & $230-270 \mathrm{~kb}$ & NRXN1 & Recurrent \\
\hline & & & & & & 10q21 & Deletion & $\begin{array}{l}2 / 111 \text { in cases, } 0 / 73 \\
\text { in controls }\end{array}$ & $90-180 \mathrm{~kb}$ & CTNNA3 & Recurrent \\
\hline & & & & & & Chr14 & Deletion & $\begin{array}{l}2 / 111 \text { in cases, } 0 / 73 \\
\text { in controls }\end{array}$ & $400-500 \mathrm{~kb}$ & FSCB & Recurrent \\
\hline & & & & & & Chr21 & Duplication & $\begin{array}{l}1 / 111 \text { in cases, } 0 / 73 \\
\text { in controls }\end{array}$ & $170-180 \mathrm{~kb}$ & KCNE1-KCNE2-RCAN1 & De novo \\
\hline \multirow{4}{*}{$\begin{array}{l}\text { Fernandez et al., } \\
2012 \text { [150] }\end{array}$} & \multirow{4}{*}{$\begin{array}{l}460(148 \text { trios }) / 1131 \\
(436 \text { trios })\end{array}$} & \multirow{4}{*}{ European } & \multirow{4}{*}{$\begin{array}{l}\text { Genomewide SNP } \\
\text { genotyping }\end{array}$} & \multirow{4}{*}{ Rare CNVs $(<1 \%)$} & \multirow{4}{*}{ 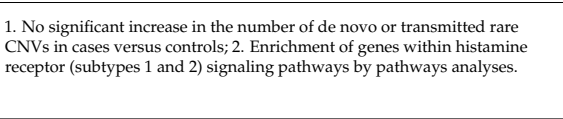 } & Chr5 & Duplication & & $51.8 \mathrm{Mb}$ & 447 RefSeq & De nого \\
\hline & & & & & & $6 \mathrm{p} 25.3$ & Duplication & & $316 \mathrm{~kb}$ & 1 RefSeq gene & De novo \\
\hline & & & & & & $20 \mathrm{p} 13$ & Deletion & & $1.2 \mathrm{Mb}$ & 27 Reffeq genes & De novo \\
\hline & & & & & & $22 q 11.21$ & Duplication & & $2.5 \mathrm{Mb}$ & 56 RefSeq genes & De nого \\
\hline \multirow[t]{2}{*}{$\begin{array}{l}\text { Nag et al., } 2013 \\
\text { [153] }\end{array}$} & \multirow[t]{2}{*}{$232 / 234$} & \multirow[t]{2}{*}{ Latin American } & \multirow[t]{2}{*}{$\begin{array}{l}\text { Genomewide SNP } \\
\text { genotyping }\end{array}$} & \multirow[t]{2}{*}{ Large CNVs } & \multirow{2}{*}{$\begin{array}{l}\text { 1. The rearrangements of COL8A1 and NRXN1 have a nominal significance; } \\
\text { 2. Cases with higher large CNV burden: } 25 / 232 \text { in TS; } 15 / 234 \text { in controls } \\
p=0.006) \text {. }\end{array}$} & $3 q 12.1$ & Duplication & $\begin{array}{l}7 / 232 \text { in cases, } \\
0 / 234 \text { in controls } \\
p=0.004\end{array}$ & $\sim 600 \mathrm{~kb}$ & COLBA1 & De novo \\
\hline & & & & & & $2 \mathrm{p} 16$ & Deletion & $\begin{array}{l}4 / 232 \text { in cases, } \\
0 / 234 \text { in controls } \\
p=0.03\end{array}$ & $\sim 400 \mathrm{~kb}$ & NRXN1 & De novo \\
\hline $\begin{array}{l}\text { McGrath et al, } 2014 \\
\text { [154] }\end{array}$ & $\begin{array}{l}1086 \mathrm{TS}, 1613 \\
\text { OCD } / 1789\end{array}$ & European & $\begin{array}{l}\text { Genomewide SNP } \\
\text { genotyping }\end{array}$ & Large, rare CNVs & 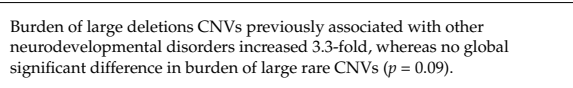 & $16 p 13.11$ & Deletion & $\begin{array}{l}5 \text { cases deletions in } \\
\text { 16ppisill locus, } \\
\text { 3deletons are } \\
\text { de novo }\end{array}$ & $>500 \mathrm{~kb}$ & & De novo \\
\hline $\begin{array}{l}\text { Bertelesen et al, } \\
2016[155]\end{array}$ & $1181 / 118,730$ & European & $\begin{array}{l}\text { qPCR or } \\
\text { genome-wide } \\
\text { genotyping }\end{array}$ & AADAC deletion & $\begin{array}{l}\text { AADAC deletion association test: } p=4.6 \times 10^{-4} ; \mathrm{OR}=2.1 ; 95 \% \mathrm{CI} \\
(1.37-3.07) \text {. }\end{array}$ & $3 q 25.1$ & Deletion & $\begin{array}{l}43 / 1181(1.82 \%) \text { in } \\
\text { TS cases, } \\
\text { 2340/118,730(0.99\%) } \\
\text { in controls }\end{array}$ & $\sim 36 \mathrm{~kb}$ & AADAC & Recurrent \\
\hline \multirow{2}{*}{$\begin{array}{l}\text { Huang et al, } 2017 \\
\text { [156] }\end{array}$} & \multirow{2}{*}{$2434 / 4093$} & \multirow{2}{*}{ European } & \multirow{2}{*}{$\begin{array}{l}\text { Genomemide SNP } \\
\text { genotyping }\end{array}$} & \multirow{2}{*}{ Rare $\mathrm{CNVs} \geq 30 \mathrm{~kb}$} & \multirow{2}{*}{ 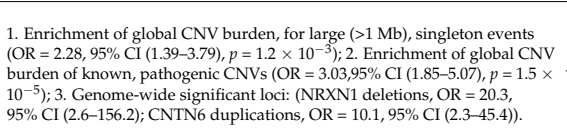 } & $3 \mathrm{p} 26$ & Duplication & $\begin{array}{l}12 / 2434(0.49 \%) \text { in } \\
\text { cases, } 2 / 4093) \\
(0.05 \%) \text { in controls }\end{array}$ & $\sim 640 \mathrm{~kb}$ & CNTN6 & Recurrent \\
\hline & & & & & & $2 \mathrm{p} 16$ & Deletion & $\begin{array}{l}12 / 2434(0.49 \%) \text { in } \\
\text { cases, } 1 / 40993 \text { (a. } \\
(0.02 \%) \text { in controls }\end{array}$ & & NRXN1 & \\
\hline
\end{tabular}




\section{Whole Exome/Genome Sequencing Studies of TS and Other Psychiatric Disorders}

Whole exome sequencing (WES) is a fast and cost-effective method by sequencing all coding regions of the entire human genome to detect rare deleterious variants, which disrupt encoded protein function. Whole genome sequencing (WGS) is to sequence the entire genome, including intron, exon, flanking sequence and interval regions. Unlike GWASs that identify common variants (frequency $\geq 5 \%$ ), WES/WGS are used to identify rare (frequency $\leq 1 \%$ ) and novel variants genome-wide. WES has achieved great success in Mendelian disorders [157]; but also used as an effective means to identify loci for complex traits or diseases [158]; and these protein-coding regions contain $85 \%$ of disease-causative mutations, even if they only cover less than $2 \%$ of the entire genome [159-161]. Coming after WES, WGS allows to identify private genetic variants, small insertions and deletions (indels), more complex $\mathrm{CNVs}$, and other structural alterations; and most of these variants reside in the $\sim 98 \%$ noncoding genome largely unexplored by SNP microarray and WES studies. With the application of WES/WGS, some rare mutations including de novo point mutations, gene-disrupting structural mutations have been found in psychiatric disorders [162-165], in which loss of functional variants (nonsense, splice-site variants), and increased burden of de novo mutations, have been shown to play an important role in etiology of psychiatric disorders [165]. 
Table 5. Main whole exome sequencing/whole genome sequencing (WES/WGS) findings in major psychiatric disorders.

\begin{tabular}{|c|c|c|c|c|c|c|c|}
\hline Diseases & Technology & Study Design & Sample Size & Project & Finding & Year & Reference \\
\hline ASD & WES & Case-control & $\begin{array}{l}3871 \text { ASD cases and } 9937 \text { controls } \\
\text { (15,480 DNA samples) }\end{array}$ & $\begin{array}{l}\text { Autism Sequencing } \\
\text { Consortium (ASC) }\end{array}$ & $\begin{array}{l}33 \text { ASD risk genes, and rare coding variations enriched in } 107 \text { genes } \\
\text { implicated in synaptic, transcriptional, and chromatin remodeling } \\
\text { pathways; de novo loss-of-function mutations in over } 5 \% \text { of autistic } \\
\text { subjects. }\end{array}$ & 2014 & [166] \\
\hline ASD & WES & Family study & $\begin{array}{l}2517 \text { families (2508 probands, } \\
1911 \text { siblings, } 5034 \text { parents) }\end{array}$ & $\begin{array}{l}\text { Simons Simplex Collection } \\
\text { (SSC) }\end{array}$ & $\begin{array}{l}27 \text { ASD associated genes; } 13 \% \text { of de novo (DN) missense mutations and } \\
42 \% \text { of DN likely gene-disrupting (LGD) mutations contributed to } 12 \% \\
\text { and 9\% of diagnoses, respectively. Including copy number variants, } \\
\text { coding DN mutations contribute to about } 30 \% \text { of all simplex and } 45 \% \text { of } \\
\text { female diagnoses. }\end{array}$ & 2014 & [167] \\
\hline ASD & SNP chip and WES & Family study & 2591 families (10,220 individuals) & SSC, ASC & $\begin{array}{l}\text { Small de novo deletions overlaps high effect with de novo loss of } \\
\text { function; Identified } 71 \text { ASD risk loci, including } 6 \mathrm{CNV} \text { regions and } \\
65 \text { risk genes. }\end{array}$ & 2015 & [168] \\
\hline ASD & WES & Family study & 5947 families (4032 trios, 1918 quads) & SSC, ASC & $\begin{array}{l}\text { Identified } 7.5 \% \text { of de novo mutations as postzygotic mosaic mutations } \\
\text { (PZMs); Damaging, nonsynonymous PZMs within critical exons of } \\
\text { prenatally expressed genes were more common in ASD probands than } \\
\text { controls }\left(p<1 \times 1 \times 10^{-6}\right) \text {, and genes carrying these PZMs were enriched } \\
\text { for expression in the amygdala }\left(p=5.4 \times 10^{-3}\right) \text {. }\end{array}$ & 2017 & [169] \\
\hline sCZ & WES & Case-control & 2536 SCZ and 2543 controls & $\begin{array}{l}\text { Swedish SCZ case-control } \\
\text { study via Hospital } \\
\text { Discharge Register }\end{array}$ & $\begin{array}{l}\text { Polygenic burden of SCZ primarily arising from rare disruptive } \\
\text { mutations distributed across many genes and enrichment in the } \\
\text { voltage-gated calcium ion channel and the signaling complex formed by } \\
\text { the activity-regulated cytoskeleton-associated (ARC) scaffold protein of } \\
\text { the postsynaptic density (PSD). }\end{array}$ & 2014 & [170] \\
\hline sCZ & WES & $\begin{array}{l}\text { Combined family } \\
\text { and case-control } \\
\text { study }\end{array}$ & 4264 cases, 9343 controls and 1077 trios & $\begin{array}{l}\text { UK10K schizophrenia } \\
\text { analysis (UK, Finnish), } \\
\text { Swedish schizophrenia } \\
\text { case-control study }\end{array}$ & $\begin{array}{l}\text { Histone H3K4 methylation pathway is associated with SCZ; } \\
\text { Genome-wide significant association between rare loss-of-function (LoF) } \\
\text { variants in SETD1A and risk for schizophrenia }\left(p=3.3 \times 10^{-9}\right) \text {. }\end{array}$ & 2016 & [171] \\
\hline scz & WES & Case-control & $\begin{array}{l}4946 \text { SCZ, } 6242 \text { controls, and } 1144 \text { with } \\
\text { other psychiatric illnesses }\end{array}$ & $\begin{array}{l}\text { Swedish SCZ case-control } \\
\text { study via Hospital } \\
\text { Discharge Register }\end{array}$ & $\begin{array}{l}\text { Ultra rare gene-disruptive and putatively protein-damaging variants } \\
\text { were more abundant in schizophrenia cases than controls } \\
\left(p=1.3 \times 10^{-10}\right) \text {. }\end{array}$ & 2016 & [172] \\
\hline sCZ & WES & $\begin{array}{l}\text { Meta-analysis for } \\
\text { combined SNVs and } \\
\text { CNVs }\end{array}$ & $\begin{array}{l}4133 \mathrm{SCZ} \text { and } 9274 \text { controls (4,133 SCZ } \\
\text { and } 9274 \text { controls AND } 1077 \text { trios; } 6882 \\
\text { cases and } 11,255 \text { controls using CNVs) }\end{array}$ & $\begin{array}{l}\text { UK10K, INTERVAL, Finnish } \\
\text { SCZ STUDY, Swedish SCZ } \\
\text { Study }\end{array}$ & $\begin{array}{l}\text { Rare, damaging variants contribute to the risk of schizophrenia both } \\
\text { with and without intellectual disability; and support an overlap of } \\
\text { genetic risk between schizophrenia and other neurodevelopmental } \\
\text { disorders. }\end{array}$ & 2017 & [173] \\
\hline BPD & WES & $\begin{array}{l}\text { Combined family } \\
\text { and case-control } \\
\text { study }\end{array}$ & $\begin{array}{l}8 \text { families ( } 36 \text { BPD), independent } \\
\text { case-control samples consisting of } \\
3541 \text { BPD cases and } 4774 \text { controls }\end{array}$ & $\begin{array}{l}\text { Swedish Exome Sequencing } \\
\text { Study; BRIDGES }\end{array}$ & $\begin{array}{l}84 \text { rare (frequency }<1 \% \text { ), damaging variants segregating within families; } \\
\text { the case-control meta-analyses yielded } 19 \text { genes that were nominally } \\
\text { associated with BPD; overlap of potential risk genes with autism and } \\
\text { schizophrenia. }\end{array}$ & 2016 & [174] \\
\hline BPD & WES & & 4 families (15 individuals) & $\begin{array}{l}\text { NIMH Bipolar Genetics } \\
\text { Initiativee }\end{array}$ & $\begin{array}{l}14 \text { variants in } 14 \text { genes were associated with bipolar disorder when } \\
\text { tested against } 2545 \text { unaffected controls and } 2543 \text { patients with } \\
\text { schizophrenia }(p<0.05 \text { after Bonferroni correction). }\end{array}$ & 2017 & [175] \\
\hline
\end{tabular}


Table 5. Cont

\begin{tabular}{|c|c|c|c|c|c|c|c|}
\hline Diseases & Technology & Study Design & Sample Size & Project & Finding & Year & Reference \\
\hline MDD & WES & $\begin{array}{l}\text { Combined family } \\
\text { and case-control } \\
\text { linkage and } \\
\text { association studies }\end{array}$ & $\begin{array}{l}\text { Discovery cohort: } 2393 \text { individuals; } \\
\text { Replication cohort: } 1604 \text { individuals }\end{array}$ & $\begin{array}{l}\text { Discovery: the Erasmus } \\
\text { Rucphen Family (ERF) } \\
\text { study for depressive } \\
\text { symptoms; Replication: } \\
\text { Rotterdam Study for } \\
\text { depressive symptoms }\end{array}$ & $\begin{array}{l}\text { Missense c.1114C }>\mathrm{T} \text { mutation (rs115482041) in the RCL1 gene } \\
\text { segregating with depression across multiple generations. Rs } 115482041 \\
\text { showed siggificant association with depressive symptoms }(\mathrm{N}=2393 \text {, } \\
\beta \mathrm{T} \text {-allele }=2.33, p \text {-value }=1 \times 10^{-4} \text { ) and explained } 2.9 \% \text { of the estimated } \\
\text { genetic variance of depressive symptoms }(22 \%) \text { in ERF; and significant } \\
\text { association with depressive symptoms in samples from the independent } \\
\text { population-based Rotterdam study }(\mathrm{N}=1604, \beta \mathrm{T} \text {-allele }=3.60, \\
\left.p \text {-value }=3 \times 10^{-2}\right) \text {. }\end{array}$ & 2017 & [176] \\
\hline MDD & WES & $\begin{array}{l}\text { Combined family } \\
\text { and case-control } \\
\text { study }\end{array}$ & $\begin{array}{l}\text { Discovery cohort: } 1265 \text { individuals } \\
\text { Replication cohort: } 3612 \text { individuals }\end{array}$ & $\begin{array}{l}\text { Discovery cohort: } \\
\text { Rotterdam Study for } \\
\text { depressive symptoms; } \\
\text { Replication cohort: Erasmus } \\
\text { Rucphen Family } \\
\text { (ERF) study }\end{array}$ & $\begin{array}{l}\text { A missense Asn396Ser mutation (rs77960347) in the endothelial lipase } \\
\text { (LIPG) gene, occurring with an allele frequency of } 1 \% \text { in the general } \\
\text { population, which was significantly associated with depressive } \\
\left.\text { symptoms ( } p \text {-value }=5.2 \times 10^{-8}, \beta=7.2\right) \text {. Replication in three } \\
\text { independent data sets }(\mathrm{N}=3612) \text { confirmed the association of Asn396Ser } \\
\left.\text { (p-value }=7.1 \times 10^{-3}, \beta=2.55\right) \text { with depressive symptoms. }\end{array}$ & 2017 & [177] \\
\hline MDD & WES & $\begin{array}{l}\text { Combined family } \\
\text { and case-control } \\
\text { study }\end{array}$ & $\begin{array}{l}\text { Discovery: } 1999 \text { individuals; Replication: } \\
2356 \text { individuals }\end{array}$ & $\begin{array}{l}\text { Discovery: the Erasmus } \\
\text { Rucphen Family (ERF) } \\
\text { study for depressive } \\
\text { symptoms; Replication: } \\
\text { Rotterdam Study for } \\
\text { depressive symptoms }\end{array}$ & $\begin{array}{l}\text { Rare nonsynonymous variants in NKPD1 is associated with depressive } \\
\text { symptoms in discovery cohort }\left(p=3.7 \times 10^{-8}\right) \text {; variants explained } 0.9 \% \\
\text { of the age- and sex-adjusted variance and } 3.8 \% \text { of heritability of } \\
\text { depressive symptoms in the ERF population; meta-analysis of the } \\
\text { discovery and replication studies improved the association signal } \\
\left(p=1.0 \times 10^{-9}\right) \text {. }\end{array}$ & 2017 & [178] \\
\hline ASD & WGS & Family study & 2626 ASD cases and 2579 family controls & $\begin{array}{l}\text { AGRE, autism Treatment } \\
\text { Network, Genomes to } \\
\text { Outcomes Study; Baby } \\
\text { Siblings Research } \\
\text { Consortium, The Autism } \\
\text { Simplex Collection, Infant } \\
\text { Sibling Study, Pathways } \\
\text { in ASD }\end{array}$ & $\begin{array}{l}\text { An average of } 73.8 \text { de novo SNVs and } 12.6 \text { de novo insertions and } \\
\text { deletions or CNVs per ASD subject; } 18 \text { new candidate ASD-risk genes } \\
\text { were identified. In } 294 \text { of } 2620(11.2 \% \text { ) of ASD cases, a molecular basis } \\
\text { could be determined and } 7.2 \% \text { of these carried copy number variations } \\
\text { and/or chromosomal abnormalities, emphasizing the importance of } \\
\text { detecting all forms of genetic variation as diagnostic and therapeutic } \\
\text { targets in ASD. }\end{array}$ & 2017 & [179] \\
\hline BPD & WGS & Family study & $\begin{array}{l}41 \text { families ( } 200 \text { individuals) and } \\
254 \text { individuals as controls }\end{array}$ & NIMH & $\begin{array}{l}\text { An increased burden of rare variants in genes encoding neuronal ion } \\
\text { channels, including subunits of GABAA receptors and voltage-gated } \\
\text { calcium channels; most of the risk variants in noncoding predicted } \\
\text { regulatory effects. }\end{array}$ & 2015 & [180] \\
\hline SCZ & WGS & Family study & 9 multiplex families (90 individuals) & Coriell Institute in Camden & $\begin{array}{l}\text { In one family, seven siblings with schizophrenia spectrum disorders } \\
\text { each carry a novel private missense variant within the SHANK2 gene. In } \\
\text { another family, four affected siblings and their unaffected mother each } \\
\text { carry a novel private missense variant in the SMARCA1 gene on the X } \\
\text { chromosome. }\end{array}$ & 2016 & [181] \\
\hline MDD & WGS & $\begin{array}{l}\text { Case-control, low } \\
\text { coverage WGS }\end{array}$ & $\begin{array}{l}\text { Discovery: } 5303 \text { cases, } 5337 \text { controls } \\
\text { (Chinese women); Replication cohort 1: } \\
\text { a separate Han Chinese cohort of } \\
3231 \text { cases with recurrent MDD, and } \\
3186 \text { controls; Replication cohort 2: } \\
9240 \text { European MDD cases and } \\
9519 \text { controls }\end{array}$ & CONVERGE Consortium & 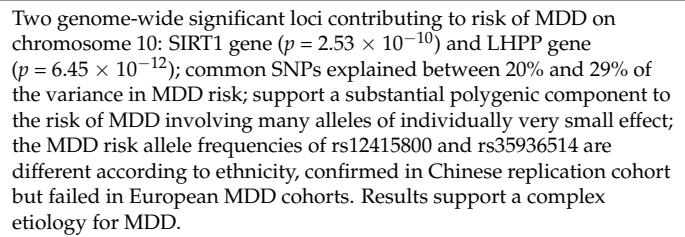 & 2015-2017 & [182-185] \\
\hline
\end{tabular}


Some major studies and findings of WES and WGS in psychiatric disorders are summarized in Table 5. So far, the application of WES has generated the most significant results in ASD than in any other psychiatric disorders, and multiple large scale studies have identified numerous candidate genes for ASD [166,170,171,174,186-195]. Compared to WES, WGS studies are much newer and with fewer number of studies and with smaller sample sizes for current studies. However, with reduced cost and improved methodologies, the application of WGS has been rapidly increased in genetic studies of complex disorders [179-181,196-198]. WES/WGS studies have further demonstrated that psychiatric disorders like SCZ, BPD, ASD belong to complex traits, rather than monogenetic disorders; and the underlying pathogenic mechanisms and pathways are perplexing. There are fewer studies of WES/WGS in TS. Sundaram et al. performed WES in ten members of one pedigree with seven affected by TS; and identified three novel nonsynonymous variants within MRPL3, DNAJC13 and OFCC1 genes [199]. Willsey et al. performed WES in two TS cohorts (325 trios from the Tourette International Collaborative Genetics cohort; 186 trios from the Tourette Syndrome Association International Consortium on Genetics), and suggested that de novo damaging variants found in approximately 400 genes may contribute to genetic risk in $12 \%$ of clinical cases of TS; and they particularly reported 4 likely risk genes for TS, i.e., WWC1 (WW and C2 domain containing 1), CELSR3 (Cadherin EGF LAG seven-pass G-type receptor 3), NIPBL (Nipped-B-like), and FN1 (fibronectin 1) [200]. Eriguchi et al. identified 30 de novo mutations, including four missense mutations (RICTOR, STRIP2, NEK10, and TNRC6A genes) in WES of nine trio families and one quartet family of TS [201]. Sun et al. identified a nonsense mutation through WES in the PNKD gene segregating with TS and Tic disorders in six out of nine members in a three-generation TD multiplex family [202]. These five above-mentioned candidate genes are enriched in CSTC regions, which are implicated TS; and their expression levels vary in different development stages, suggesting that disruptive protein function of those genes might affect neuronal development or activity in these brain structures [201,202]. Compared to ASD, SCZ and MDD, WES/WGS in TS are limited by the small sample sizes [199-202]. Further studies with enlarged sample size will be helpful to understand the genetic architecture of TS and its overlap with other neuropsychiatric disorders.

\section{Epigenetics and TS}

Decades of genetic research have shown that there are no direct correlations between genotypes and phenotypes in psychiatric disorders; and there ought to be missing pieces of information between genomic variations and disease phenotypes, i.e., changes of genomes will only become effective through transcsriptome, epigenome and result in phenotypic outcomes. Epigenetics refers to the ongoing regulation of gene expression, which includes structural modification of chromatin, post-translational modification of histones (i.e., acetylation and methylation), chemical modification of DNA through methylation or hydroxymethylation of cysteins, as well as expression of interfering non-coding RNAs (i.e., miRNAs and long-non-coding RNAs) [203,204]. These epigenetic mechanisms allow reprogramming of the genome upon environmental inputs at specific time-points during development and through lifetime. The epigenetic changes triggered by early life events stand as a valuable hypothesis of the environmentally induced behavioral changes.

Epigenetic regulation has been shown to have an impact on the development of many neuropsychiatric disorders [205,206], and to play a pivotal role in embryonic and adult neurogenesis [207]. Some studies on epigenetic processes in the expression and inheritance of behaviors have helped us to further understand the complexity of brain functions [208]. Abelson et al. identified a noncoding RNA variant (var321) at the binding site for microRNA hsa-miR-189 in two unrelated TS patients on chromosomal 13 [51] (see above). In 2015, Rizzo et al. found that miR-429 was significantly underexpressed in TS patients and suggested as an useful molecular biomarker to aid TS diagnosis in the future [209]. Another study suggested that methylation levels of the DRD2 gene were higher in adults with TS than in sex-, age-matched controls [210]; and methylation of DRD2 was positively correlated with tic severity. However, methylation of $D A T$ was negatively correlated with 
tic severity in the same study [210]. State et al. reported that there might be relationship between chromosome 18(q21-q22) inversion and epigenetic mechanism in a 12 year old boy with TS and OCD [140]. The results from the first epigenome-wide association study, which investigated DNA methylation in patients with tic disorders, suggested that the top hits of methylation signal were enriched for genes involved in brain-specific and developmental processes [211]. Delgado et al. did not find significant methylation difference in TS patients compared with controls in a region of chromosome 8 for KCNK9 and TRAPPC9 genes [212].

\section{Conclusions}

TS is a complex disorder with highly variable phenotypic manifestations and high frequency of comorbidities. It is more common in males than in females. Family and twin studies have shown that genetic factors play an important role in the pathogenesis of TS. Candidate genes studies have shown that multiple genes (DRD2, DRD4, 5-HT2C, SERT) in multiple neural systems, including dopaminergic, serotonergic, histaminergic pathways, might be associated with pathogenesis of TS, but results are not yet convincing enough. In recent years, several new candidate genes, e.g., SLITRK1, IMMP2L, CNTNAP2, NLGN4, have been identified through linkage studies and structural genomic aberrations, in which very rare genetic variants with large effects were found in TS patients and families.

Compared to genetic studies of other psychiatric disorders, TS studies are currently still largely limited by the relatively small sample sizes, because of the complexity and heterogeneity in clinical manifestation. We expect that more rare and common variants with various effects underlying the genetic susceptibility of TS will be discovered through larger-scale international collaborative projects in the near future. Combinational analyses of common variants with rare variants, structural variations and CNVs, plus epigenetic factors; i.e., integrative "multi-omics" together with environmental factor analyses $[213,214]$ will be the future direction. As promising starts, four large collaborative groups with joint effort and multiple resources have been developed for TS genetic research, focusing on existing large well-characterized patient cohorts, which include (1) the Tourette Syndrome Association International Consortium for Genetics (TSAICG) [215]—genomewide association studies for TS; (2) the Tourette international collaborative genetics (TIC genetics) study-whole exome sequencing in families with TS [216], which is funded by the National Institute of Mental Health (NIMH) in the USA; (3) the European multicentre tics in children (EMTICS) study-exploring gene-environment interactions that underlie TS etiology, which is funded by the European Commission under the Seventh Framework Programme, including 17 clinical sites from across Europe [217]; (4) TS-EUROTRAIN — coordinating large-scale studies and training the next generation of experts for TS, supported by the European Commission [218,219]; (5) Of particular interest in this field, the PsychENCODE project has been created and developed by an international consortium to provide an enhanced framework of regulatory genomic elements (promoters, enhancers, silencers and insulators), catalog epigenetic modifications and quantify coding and non-coding RNA and protein expression in tissue and cell-type-specific samples from healthy (neurotypical) control and disease-affected post-mortem human brains, as well as functionally characterize disease-associated regulatory elements and variants in model systems. [220]. The Project is currently focusing on three major psychiatric disorders: ASD, BPD and SCZ, for example, 98 of the 108 independently associated loci were found in non-coding region in SCZ GWAS $[96,221]$ suggesting that the PsychENCODE project will be a valuable platform to study the epigenetics of psychiatric disorders in the future, including TS studies, in which some preliminary results indicated that epigenetics might play a role in TS as well [51,140,209-211].

In the near future, GWAS by SNP arrays will most likely be gradually replaced by WGS, with increased power by including rare variants in the genetic analyses. For many years, genotyping technology was the limiting step to genetic discoveries, but now discovery is limited by phenotypic descriptors that could link with genetic data to allow disease stratification, which might be more aligned with treatments; therefore, deep phenotyping aligned with genetic studies will also facilitate new discoveries for disease risk and mechanism. 
Although with limited results, epigenetic research has shown promising hope to link the genomic variations with environmental exposures and disease outcomes, particularly for psychiatric disorders and behavioral phenotypes. For TS, further studies with larger sample size could focus on further understanding of the effect of dynamic epigenome on the regulation of developmental genes and behaviors. Additional large-scale studies could also aim to disentangle common versus disorder-specific genomic and epigenomic variations in TS with other psychiatric and behavioral phenotypes. Understanding the mechanism behind the sex differences in TS may also help us better understand the regulation of gene expression in the brain and its implication in TS pathogenesis because TS is a male-biased disease.

Acknowledgments: Yanjie Qi would like to thank the fellowship provided by the Beijing Anding Hospital for her study in Montreal, Canada. The co-authors would like to thank the editors and reviewers for their support and help for this manuscript.

Author Contributions: Y.Q. and L.X. planned and drafted the manuscript; L.X. revised and finalized; Y.Z. and Z.L. advised and commented on the manuscript.

Conflicts of Interest: The authors declare no conflict of interest.

\section{References}

1. American Psychiatric Association. Diagnostic and Statistical Manual of Mental Disorders, 5th ed.; DSM Library; American Psychiatric Association: Lake St. Louis, MO, USA, 2013; ISBN 0-89042-555-8.

2. Eapen, V.; Cavanna, A.E.; Robertson, M.M. Comorbidities, Social Impact, and Quality of Life in Tourette Syndrome. Front. Psychiatry 2016. [CrossRef] [PubMed]

3. Bloch, M.H.; Leckman, J.F. Clinical course of Tourette syndrome. J. Psychosom. Res. 2009, 67, 497-501. [CrossRef] [PubMed]

4. Peterson, B.S.; Leckman, J.F. The temporal dynamics of tics in Gilles de la Tourette syndrome. Biol. Psychiatry 1998, 44, 1337-1348. [CrossRef]

5. Conelea, C.A.; Woods, D.W. The influence of contextual factors on tic expression in Tourette's syndrome: A review. J. Psychosom. Res. 2008, 65, 487-496. [CrossRef] [PubMed]

6. Bloch, M.H.; Peterson, B.S.; Scahill, L.; Otka, J.; Katsovich, L.; Zhang, H.; Leckman, J.F. Adulthood Outcome of Tic and Obsessive-Compulsive Symptom Severity in Children With Tourette Syndrome. Arch. Pediatr. Adolesc. Med. 2006, 160, 65-69. [CrossRef] [PubMed]

7. Hassan, N.; Cavanna, A.E. The prognosis of Tourette syndrome: Implications for clinical practice. Funct. Neurol. 2012, 27, 23-27. [PubMed]

8. Rizzo, R.; Gulisano, M.; Calì, P.V.; Curatolo, P. Long term clinical course of Tourette syndrome. Brain Dev. 2012, 34, 667-673. [CrossRef] [PubMed]

9. $\quad$ Leckman, J.F.; Zhang, H.; Vitale, A.; Lahnin, F.; Lynch, K.; Bondi, C.; Kim, Y.-S.; Peterson, B.S. Course of Tic Severity in Tourette Syndrome: The First Two Decades. Pediatrics 1998, 102, 14-19. [CrossRef] [PubMed]

10. Bloch, M.H.; Sukhodolsky, D.G.; Leckman, J.F.; Schultz, R.T. Fine-motor skill deficits in childhood predict adulthood tic severity and global psychosocial functioning in Tourette's syndrome. J. Child Psychol. Psychiatry 2006, 47, 551-559. [CrossRef] [PubMed]

11. Bloch, M.H.; Leckman, J.F.; Zhu, H.; Peterson, B.S. Caudate volumes in childhood predict symptom severity in adults with Tourette syndrome. Neurology 2005, 65, 1253-1258. [CrossRef] [PubMed]

12. Hirschtritt, M.E.; Lee, P.C.; Pauls, D.L.; Dion, Y.; Grados, M.A.; Illmann, C.; King, R.A.; Sandor, P.; McMahon, W.M.; Lyon, G.J.; et al. Lifetime Prevalence, Age of Risk, and Genetic Relationships of Comorbid Psychiatric Disorders in Tourette Syndrome. JAMA Psychiatry 2015, 72, 325-333. [CrossRef] [PubMed]

13. Kumar, A.; Trescher, W.; Byler, D. Tourette Syndrome and Comorbid Neuropsychiatric Conditions. Curr. Dev. Disord. Rep. 2016, 3, 217-221. [CrossRef] [PubMed]

14. Freeman, R.D.; Fast, D.K.; Burd, L.; Kerbeshian, J.; Robertson, M.M.; Sandor, P. An international perspective on Tourette syndrome: Selected findings from 3500 individuals in 22 countries. Dev. Med. Child Neurol. 2000, 42, 436-447. [CrossRef] [PubMed]

15. Cavanna, A.E.; Servo, S.; Monaco, F.; Robertson, M.M. The Behavioral Spectrum of Gilles de la Tourette Syndrome. JNP 2009, 21, 13-23. [CrossRef] [PubMed] 
16. Robertson, M.M. A personal 35 year perspective on Gilles de la Tourette syndrome: Prevalence, phenomenology, comorbidities, and coexistent psychopathologies. Lancet Psychiatry 2015, 2, 68-87. [CrossRef]

17. Robertson, M.M.; Eapen, V.; Cavanna, A.E. The international prevalence, epidemiology, and clinical phenomenology of Tourette syndrome: A cross-cultural perspective. J. Psychosom. Res. 2009, 67, 475-483. [CrossRef] [PubMed]

18. Scharf, J.M.; Miller, L.L.; Gauvin, C.A.; Alabiso, J.; Mathews, C.A.; Ben-Shlomo, Y. Population prevalence of Tourette syndrome: A systematic review and meta-analysis. Mov. Disord. 2015, 30, 221-228. [CrossRef] [PubMed]

19. Knight, T.; Steeves, T.; Day, L.; Lowerison, M.; Jette, N.; Pringsheim, T. Prevalence of Tic Disorders: A Systematic Review and Meta-Analysis. Pediatr. Neurol. 2012, 47, 77-90. [CrossRef] [PubMed]

20. Zilhão, N.R.; Olthof, M.C.; Smit, D.J.A.; Cath, D.C.; Ligthart, L.; Mathews, C.A.; Delucchi, K.; Boomsma, D.I.; Dolan, C.V. Heritability of tic disorders: A twin-family study. Psychol. Med. 2016, 1-12. [CrossRef] [PubMed]

21. Martino, D.; Macerollo, A.; Leckman, J.F. Chapter Nine-Neuroendocrine Aspects of Tourette Syndrome. In Advances in the Neurochemistry and Neuropharmacology of Tourette Syndrome; International Review of Neurobiology; Cavanna, D.M., Cavanna, A.E., Eds.; Academic Press: Cambridge, MA, USA, 2013; Volume 112, pp. 239-279.

22. Yang, J.; Hirsch, L.; Martino, D.; Jette, N.; Roberts, J.; Pringsheim, T. The prevalence of diagnosed tourette syndrome in Canada: A national population-based study. Mov. Disord. 2016, 31, 1658-1663. [CrossRef] [PubMed]

23. Schlander, M.; Schwarz, O.; Rothenberger, A.; Roessner, V. Tic disorders: Administrative prevalence and co-occurrence with attention-deficit/hyperactivity disorder in a German community sample. Eur. Psychiatry 2011, 26, 370-374. [CrossRef] [PubMed]

24. Pauls, D.L.; Fernandez, T.V.; Mathews, C.A.; State, M.W.; Scharf, J.M. The Inheritance of Tourette Disorder: A review. J. Obsessive Compuls. Relat. Disord. 2014, 3, 380-385. [CrossRef] [PubMed]

25. Mataix-Cols, D.; Isomura, K.; Pérez-Vigil, A.; Chang, Z.; Rück, C.; Larsson, K.J.; Leckman, J.F.; Serlachius, E.; Larsson, H.; Lichtenstein, P. Familial Risks of Tourette Syndrome and Chronic Tic Disorders: A Population-Based Cohort Study. JAMA Psychiatry 2015, 72, 787-793. [CrossRef] [PubMed]

26. Mathews, C.A.; Grados, M.A. Familiality of Tourette Syndrome, Obsessive-Compulsive Disorder, and Attention-DeficitHyperactivity Disorder: Heritability Analysis in a Large Sib-Pair Sample. J. Am. Acad. Child Adolesc. Psychiatry 2011, 50, 46-54. [CrossRef] [PubMed]

27. Stewart, S.E.; Illmann, C.; Geller, D.A.; Leckman, J.F.; King, R.; Pauls, D.L. A Controlled Family Study of Attention-Deficit/Hyperactivity Disorder and Tourette's Disorder. J. Am. Acad. Child Adolesc. Psychiatry 2006, 45, 1354-1362. [CrossRef] [PubMed]

28. Kurlan, R.; Behr, J.; Medved, L.; Shoulson, I.; Pauls, D.; Kidd, J.R.; Kidd, K.K. Familial Tourette's syndrome: Report of a large pedigree and potential for linkage analysis. Neurology 1986, 36, 772-776. [CrossRef] [PubMed]

29. Fabbrini, G.; Pasquini, M.; Aurilia, C.; Berardelli, I.; Breedveld, G.; Oostra, B.A.; Bonifati, V.; Berardelli, A. A large Italian family with Gilles de la Tourette syndrome: Clinical study and analysis of the SLITRK1 gene. Mov. Disord. 2007, 22, 2229-2234. [CrossRef] [PubMed]

30. Curtis, D.; Robertson, M.M.; Gurling, H.M. Autosomal dominant gene transmission in a large kindred with Gilles de la Tourette syndrome. Br. J. Psychiatry 1992, 160, 845-849. [CrossRef] [PubMed]

31. Robertson, M.M.; Gourdie, A. Familial Tourette's syndrome in a large British pedigree. Associated psychopathology, severity, and potential for linkage analysis. Br. J. Psychiatry 1990, 156, 515-521. [CrossRef] [PubMed]

32. Eapen, V.; Pauls, D.L.; Robertson, M.M. Evidence for autosomal dominant transmission in Tourette's syndrome. United Kingdom cohort study. Br. J. Psychiatry 1993, 162, 593-596. [CrossRef] [PubMed]

33. Seuchter, S.A.; Hebebrand, J.; Klug, B.; Knapp, M.; Lehmkuhl, G.; Poustka, F.; Schmidt, M.; Remschmidt, H.; Baur, M.P. Complex segregation analysis of families ascertained through Gilles de la Tourette syndrome. Genet. Epidemiol. 2000, 18, 33-47. [CrossRef]

34. Huisman-van Dijk, H.M.; van de Schoot, R.; Rijkeboer, M.M.; Mathews, C.A.; Cath, D.C. The relationship between tics, OC, ADHD and autism symptoms: A cross-disorder symptom analysis in Gilles de la Tourette syndrome patients and their family members. Psychiatry Res. 2016, 237, 138-146. [CrossRef] [PubMed] 
35. Price, R.A.; Kidd, K.K.; Cohen, D.J.; Pauls, D.L.; Leckman, J.F. A Twin Study of Tourette Syndrome. Arch. Gen. Psychiatry 1985, 42, 815-820. [CrossRef] [PubMed]

36. Hyde, T.M.; Aaronson, B.A.; Randolph, C.; Rickler, K.C.; Weinberger, D.R. Relationship of birth weight to the phenotypic expression of Gilles de la Tourette's syndrome in monozygotic twins. Neurology 1992, 42, 652-658. [CrossRef] [PubMed]

37. Bolton, D.; Rijsdijk, F.; O'Connor, T.G.; Perrin, S.; Eley, T.C. Obsessive-compulsive disorder, tics and anxiety in 6-year-old twins. Psychol. Med. 2007, 37, 39-48. [CrossRef] [PubMed]

38. Anckarsäter, H.; Lundström, S.; Kollberg, L.; Kerekes, N.; Palm, C.; Carlström, E.; Långström, N.; Magnusson, P.K.E.; Halldner, L.; Bölte, S.; et al. The Child and Adolescent Twin Study in Sweden (CATSS). Twin Res. Hum. Genet. 2011, 14, 495-508. [CrossRef] [PubMed]

39. Pinto, R.; Monzani, B.; Leckman, J.F.; Rück, C.; Serlachius, E.; Lichtenstein, P.; Mataix-Cols, D. Understanding the covariation of tics, attention-deficit/hyperactivity, and obsessive-compulsive symptoms: A population-based adult twin study. Am. J. Med. Genet. 2016, 171, 938-947. [CrossRef] [PubMed]

40. Sullivan, P.F.; Daly, M.J.; O’Donovan, M. Genetic Architectures of Psychiatric Disorders: The Emerging Picture and Its Implications. Nat. Rev. Genet. 2012, 13, 537-551. [CrossRef] [PubMed]

41. Brett, P.; Curtis, D.; Gourdie, A.; Schnieden, V.; Jackson, G.; Holmes, D.; Robertson, M.; Gurling, H. Possible linkage of Tourette syndrome to markers on short arm of chromosome 3 (C3p21-14). Lancet 1990, 336, 1076. [CrossRef]

42. The Tourette Syndrome Association International Consortium for Genetics. A Complete Genome Screen in Sib Pairs Affected by Gilles de la Tourette Syndrome. Am. J. Hum. Genet. 1999, 65, 1428-1436.

43. Zhang, H.; Leckman, J.F.; Pauls, D.L.; Tsai, C.-P.; Kidd, K.K.; Campos, M.R. Genomewide Scan of Hoarding in Sib Pairs in Which Both Sibs Have Gilles de la Tourette Syndrome. Am. J. Hum. Genet. 2002, 70, 896-904. [CrossRef] [PubMed]

44. Rivière, J.-B.; Xiong, L.; Levchenko, A.; St-Onge, J.; Gaspar, C.; Dion, Y.; Lespérance, P.; Tellier, G.; Richer, F.; Chouinard, S.; et al. Montreal Tourette Study Group Association of intronic variants of the BTBD9 gene with Tourette syndrome. Arch. Neurol. 2009, 66, 1267-1272. [CrossRef] [PubMed]

45. Boghosian-Sell, L.; Comings, D.E.; Overhauser, J. Tourette syndrome in a pedigree with a 7;18 translocation: Identification of a YAC spanning the translocation breakpoint at 18q22.3. Am. J. Hum. Genet. 1996, 59, 999-1005. [PubMed]

46. Petek, E.; Windpassinger, C.; Vincent, J.B.; Cheung, J.; Boright, A.P.; Scherer, S.W.; Kroisel, P.M.; Wagner, K. Disruption of a Novel Gene (IMMP2L) by a Breakpoint in 7q31 Associated with Tourette Syndrome. Am. J. Hum. Genet. 2001, 68, 848-858. [CrossRef] [PubMed]

47. Díaz-Anzaldúa, A.; Joober, R.; Rivière, J.-B.; Dion, Y.; Lespérance, P.; Richer, F.; Chouinard, S.; Rouleau, G.A. Tourette syndrome and dopaminergic genes: A family-based association study in the French Canadian founder population. Mol. Psychiatry 2004, 9, 272-277. [CrossRef] [PubMed]

48. Mérette, C.; Brassard, A.; Potvin, A.; Bouvier, H.; Rousseau, F.; Émond, C.; Bissonnette, L.; Roy, M.-A.; Maziade, M.; Ott, J.; et al. Significant Linkage for Tourette Syndrome in a Large French Canadian Family. Am. J. Hum. Genet. 2000, 67, 1008-1013. [CrossRef] [PubMed]

49. Simonic, I.; Gericke, G.S.; Ott, J.; Weber, J.L. Identification of genetic markers associated with Gilles de la Tourette syndrome in an Afrikaner population. Am. J. Hum. Genet. 1998, 63, 839-846. [CrossRef] [PubMed]

50. Díaz-Anzaldúa, A.; Rivière, J.-B.; Dubé, M.-P.; Joober, R.; Saint-Onge, J.; Dion, Y.; Lespérance, P.; Richer, F.; Chouinard, S.; Rouleau, G.A. Montreal Tourette Syndrome Study Group Chromosome 11-q24 region in Tourette syndrome: Association and linkage disequilibrium study in the French Canadian population. Am. J. Med. Genet. A 2005, 138A, 225-228. [CrossRef] [PubMed]

51. Abelson, J.F.; Kwan, K.Y.; O’Roak, B.J.; Baek, D.Y.; Stillman, A.A.; Morgan, T.M.; Mathews, C.A.; Pauls, D.L.; Rasin, M.-R.; Gunel, M.; et al. Sequence variants in SLITRK1 are associated with Tourette's syndrome. Science 2005, 310, 317-320. [CrossRef] [PubMed]

52. Ercan-Sencicek, A.G.; Stillman, A.A.; Ghosh, A.K.; Bilguvar, K.; O’Roak, B.J.; Mason, C.E.; Abbott, T.; Gupta, A.; King, R.A.; Pauls, D.L.; et al. L-Histidine Decarboxylase and Tourette's Syndrome. N. Engl. J. Med. 2010, 362, 1901-1908. [CrossRef] [PubMed] 
53. Paschou, P.; Feng, Y.; Pakstis, A.J.; Speed, W.C.; DeMille, M.M.; Kidd, J.R.; Jaghori, B.; Kurlan, R.; Pauls, D.L.; Sandor, P.; et al. Indications of Linkage and Association of Gilles de la Tourette Syndrome in Two Independent Family Samples: 17q25 Is a Putative Susceptibility Region. Am. J. Hum. Genet. 2004, 75, 545-560. [CrossRef] [PubMed]

54. Sun, N.; Tischfield, J.A.; King, R.A.; Heiman, G.A. Functional Evaluations of Genes Disrupted in Patients with Tourette's Disorder. Front. Psychiatry 2016. [CrossRef] [PubMed]

55. Ledonne, A.; Mercuri, N.B. Current Concepts on the Physiopathological Relevance of Dopaminergic Receptors. Front. Cell Neurosci. 2017. [CrossRef] [PubMed]

56. Hu, W.; Chen, Z. The roles of histamine and its receptor ligands in central nervous system disorders: An update. Pharmacol. Ther. 2017. [CrossRef] [PubMed]

57. Meunier, C.N.J.; Chameau, P.; Fossier, P.M. Modulation of Synaptic Plasticity in the Cortex Needs to Understand All the Players. Front. Synaptic Neurosci. 2017. [CrossRef] [PubMed]

58. Brett, P.M.; Curtis, D.; Robertson, M.M.; Gurling, H.M.D. The genetic susceptibility to Gilles de la Tourette Syndrome in a large multiple affected british kindred: Linkage analysis excludes a role for the genes coding for dopamine D1, D2, D3, D4, D5 receptors, dopamine beta hydroxylase, tyrosinase, and tyrosine hydroxylase. Biol. Psychiatry 1995, 37, 533-540. [PubMed]

59. Gelernter, J.; Kennedy, J.L.; Grandy, D.K.; Zhou, Q.Y.; Civelli, O.; Pauls, D.L.; Pakstis, A.; Kurlan, R.; Sunahara, R.K.; Niznik, H.B. Exclusion of close linkage of Tourette's syndrome to D1 dopamine receptor. Am. J. Psychiatry 1993, 150, 449-453. [PubMed]

60. Thompson, M.; Comings, D.E.; Feder, L.; George, S.R.; O’Dowd, B.F. Mutation screening of the dopamine D1 receptor gene in Tourette's syndrome and alcohol dependent patients. Am. J. Med. Genet. 1998, 81, 241-244. [CrossRef]

61. Chou, I.-C.; Tsai, C.-H.; Lee, C.-C.; Kuo, H.-T.; Hsu, Y.-A.; Li, C.-I.; Tsai, F.-J. Association analysis between Tourette's syndrome and dopamine D1 receptor gene in Taiwanese children. Psychiatr. Genet. 2004, 14, 219-221. [CrossRef] [PubMed]

62. Comings, D.E.; Comings, B.G.; Muhleman, D.; Dietz, G.; Shahbahrami, B.; Tast, D.; Knell, E.; Kocsis, P.; Baumgarten, R.; Kovacs, B.W.; et al. The Dopamine D2 Receptor Locus as a Modifying Gene in Neuropsychiatric Disorders. JAMA 1991, 266, 1793-1800. [CrossRef] [PubMed]

63. Comings, D.E.; Wu, S.; Chiu, C.; Ring, R.H.; Gade, R.; Ahn, C.; MacMurray, J.P.; Dietz, G.; Muhleman, D. Polygenic inheritance of Tourette syndrome, stuttering, attention deficit hyperactivity, conduct, and oppositional defiant disorder: The additive and subtractive effect of the three dopaminergic genes-DRD2, D beta H, and DAT1. Am. J. Med. Genet. 1996, 67, 264-288. [CrossRef]

64. Lee, C.-C.; Chou, I.-C.; Tsai, C.-H.; Wang, T.-R.; Li, T.-C.; Tsai, F.-J. Dopamine Receptor D2 Gene Polymorphisms Are Associated in Taiwanese Children With Tourette Syndrome. Pediatr. Neurol. 2005, 33, 272-276. [CrossRef] [PubMed]

65. Gelernter, J.; Pakstis, A.J.; Pauls, D.L.; Kurlan, R.; Gancher, S.T.; Civelli, O.; Grandy, D.; Kidd, K.K. Gilles de la Tourette Syndrome Is Not Linked to D2-Dopamine Receptor. Arch. Gen. Psychiatry 1990, 47, 1073-1077. [CrossRef] [PubMed]

66. Gelernter, J.; Pauls, D.L.; Leckman, J.; Kidd, K.K.; Kurlan, R. D2 Dopamine Receptor Alleles Do Not Influence Severity of Tourette's Syndrome: Results From Four Large Kindreds. Arch. Neurol. 1994, 51, 397-400. [CrossRef] [PubMed]

67. Nöthen, M.M.; Hebebrand, J.; Knapp, M.; Hebebrand, K.; Camps, A.; von Gontard, A.; Wettke-Schäfer, R.; Lisch, S.; Cichon, S.; Poustka, F.; et al. Association analysis of the dopamine D2 receptor gene in Tourette's syndrome using the haplotype relative risk method. Am. J. Med. Genet. 1994, 54, 249-252. [CrossRef] [PubMed]

68. Abdulkadir, M.; Londono, D.; Gordon, D.; Fernandez, T.V.; Brown, L.W.; Cheon, K.-A.; Coffey, B.J.; Elzerman, L.; Fremer, C.; Fründt, O.; et al. Investigation of previously implicated genetic variants in chronic tic disorders: A transmission disequilibrium test approach. Eur. Arch. Psychiatry Clin. Neurosci. 2017. [CrossRef] [PubMed]

69. He, F.; Zheng, Y.; Huang, H.-H.; Cheng, Y.-H.; Wang, C.-Y. Association between Tourette Syndrome and the Dopamine D3 Receptor Gene Rs6280. Chin. Med. J. 2015, 128, 654-658. [PubMed] 
70. Grice, D.E.; Leckman, J.F.; Pauls, D.L.; Kurlan, R.; Kidd, K.K.; Pakstis, A.J.; Chang, F.M.; Buxbaum, J.D.; Cohen, D.J.; Gelernter, J. Linkage disequilibrium between an allele at the dopamine D4 receptor locus and Tourette syndrome, by the transmission-disequilibrium test. Am. J. Hum. Genet. 1996, 59, 644-652. [PubMed]

71. Cruz, C.; Camarena, B.; King, N.; Páez, F.; Sidenberg, D.; de la Fuente, J.R.; Nicolini, H. Increased prevalence of the seven-repeat variant of the dopamine D4 receptor gene in patients with obsessive-compulsive disorder with tics. Neurosci. Lett. 1997, 231, 1-4. [CrossRef]

72. Tarnok, Z.; Ronai, Z.; Gervai, J.; Kereszturi, E.; Gadoros, J.; Sasvari-Szekely, M.; Nemoda, Z. Dopaminergic candidate genes in Tourette syndrome: Association between tic severity and $3^{\prime}$ UTR polymorphism of the dopamine transporter gene. Am. J. Med. Genet. B Neuropsychiatr. Genet. 2007, 144B, 900-905. [CrossRef] [PubMed]

73. Barr, C.L.; Wigg, K.G.; Zovko, E.; Sandor, P.; Tsui, L.-C. No evidence for a major gene effect of the dopamine D4 receptor gene in the susceptibility to Gilles de la Tourette syndrome in five Canadian families. Am. J. Med. Genet. 1996, 67, 301-305. [CrossRef]

74. Hebebrand, J.; Nöthen, M.M.; Ziegler, A.; Klug, B.; Neidt, H.; Eggermann, K.; Lehmkuhl, G.; Poustka, F.; Schmidt, M.H.; Propping, P.; et al. Nonreplication of linkage disequilibrium between the dopamine D4 receptor locus and Tourette syndrome. Am. J. Hum. Genet. 1997, 61, 238-239. [CrossRef]

75. Yoon, D.Y.; Rippel, C.A.; Kobets, A.J.; Morris, C.M.; Lee, J.E.; Williams, P.N.; Bridges, D.D.; Vandenbergh, D.J.; Shugart, Y.Y.; Singer, H.S. Dopaminergic polymorphisms in Tourette syndrome: Association with the DAT gene (SLC6A3). Am. J. Med. Genet. 2007, 144B, 605-610. [CrossRef] [PubMed]

76. Barr, C.L.; Wigg, K.G.; Zovko, E.; Sandor, P.; Tsui, L.-C. Linkage study of the dopamine D5 receptor gene and Gilles de la Tourette syndrome. Am. J. Med. Genet. 1997, 74, 58-61. [CrossRef]

77. Gelernter, J.; Vandenbergh, D.; Kruger, S.D.; Pauls, D.L.; Kurlan, R.; Pakstis, A.J.; Kidd, K.K.; Uhl, G. The Dopamine Transporter Protein Gene (SLC6A3): Primary Linkage Mapping and Linkage Studies in Tourette Syndrome. Genomics 1995, 30, 459-463. [CrossRef] [PubMed]

78. Ozbay, F.; Wigg, K.G.; Turanli, E.T.; Asherson, P.; Yazgan, Y.; Sandor, P.; Barr, C.L. Analysis of the dopamine beta hydroxylase gene in Gilles de la tourette syndrome. Am. J. Med. Genet. 2006, 141B, 673-677. [CrossRef] [PubMed]

79. Cavallini, M.C.; Di Bella, D.; Catalano, M.; Bellodi, L. An association study between 5-HTTLPR polymorphism, COMT polymorphism, and Tourette's syndrome. Psychiatry Res. 2000, 97, 93-100. [CrossRef]

80. Lam, S.; Shen, Y.; Nguyen, T.; Messier, T.L.; Brann, M.; Comings, D.; George, S.R.; O’Dowd, B.F. A Serotonin Receptor Gene (5HT1A) Variant Found in a Tourette's Syndrome Patient. Biochem. Biophys. Res. Commun. 1996, 219, 853-858. [CrossRef] [PubMed]

81. Erdmann, J.; Shimron-Abarbanell, D.; Cichon, S.; Albus, M.; Maier, W.; Lichtermann, D.; Minges, J.; Reuner, U.; Franzek, E.; Ertl, M.A.; et al. Systematic screening for mutations in the promoter and the coding region of the 5-HT1A gene. Am. J. Med. Genet. 1995, 60, 393-399. [CrossRef] [PubMed]

82. Huang, Y.; Liu, X.; Li, T.; Guo, L.; Sun, X.; Xiao, X.; Ma, X.; Wang, Y.; Collier, D.A. Cases-Control association study and transmission disequilibrium test of T102C polymorphism in 5HT2A and Tourette syndrome. Zhonghua Yi Xue Yi Chuan Xue Za Zhi 2001, 18, 11-13. [PubMed]

83. Dehning, S.; Müller, N.; Matz, J.; Bender, A.; Kerle, I.; Benninghoff, J.; Musil, R.; Spellmann, I.; Bondy, B.; Möller, H.-J.; et al. A genetic variant of HTR2C may play a role in the manifestation of Tourette syndrome. Psychiatr. Genet. 2010, 20, 35-38. [CrossRef] [PubMed]

84. Niesler, B.; Frank, B.; Hebebrand, J.; Rappold, G. Serotonin receptor genes HTR3A and HTR3B are not involved in Gilles de la Tourette syndrome. Psychiatr. Genet. 2005, 15, 303-304. [CrossRef] [PubMed]

85. Gelernter, J.; Rao, P.A.; Pauls, D.L.; Hamblin, M.W.; Sibley, D.R.; Kidd, K.K. Assignment of the 5HT7 receptor gene (HTR7) to chromosome 10q and exclusion of genetic linkage with tourette syndrome. Genomics 1995, 26, 207-209. [CrossRef]

86. Moya, P.R.; Wendland, J.R.; Rubenstein, L.M.; Timpano, K.R.; Heiman, G.A.; Tischfield, J.A.; King, R.A.; Andrews, A.M.; Ramamoorthy, S.; McMahon, F.J.; et al. Common and rare alleles of the serotonin transporter gene, SLC6A4, associated with Tourette disorder. Mov. Disord. 2013, 28, 1263-1270. [CrossRef] [PubMed]

87. Mössner, R.; Müller-Vahl, K.R.; Döring, N.; Stuhrmann, M. Role of the novel tryptophan hydroxylase-2 gene in Tourette syndrome. Mol. Psychiatry 2007, 12, 617-619. [CrossRef] [PubMed] 
88. Adamczyk, A.; Gause, C.D.; Sattler, R.; Vidensky, S.; Rothstein, J.D.; Singer, H.; Wang, T. Genetic and functional studies of a missense variant in a glutamate transporter, SLC1A3, in Tourette syndrome. Psychiatr. Genet. 2011, 21, 90-97. [CrossRef] [PubMed]

89. Crane, J.; Fagerness, J.; Osiecki, L.; Gunnell, B.; Stewart, S.E.; Pauls, D.L.; Scharf, J.M. Family-based Genetic Association Study of DLGAP3 in Tourette Syndrome. Am. J. Med. Genet. B Neuropsychiatr. Genet. 2011, 156B, 108-114. [CrossRef] [PubMed]

90. Karagiannidis, I.; Dehning, S.; Sandor, P.; Tarnok, Z.; Rizzo, R.; Wolanczyk, T.; Madruga-Garrido, M.; Hebebrand, J.; Nöthen, M.M.; Lehmkuhl, G.; et al. Support of the histaminergic hypothesis in Tourette Syndrome: Association of the histamine decarboxylase gene in a large sample of families. J. Med. Genet. 2013, 50, 760-764. [CrossRef] [PubMed]

91. Xu, C.; Ozbay, F.; Wigg, K.; Shulman, R.; Tahir, E.; Yazgan, Y.; Sandor, P.; Barr, C.L. Evaluation of the genes for the adrenergic receptors $\alpha 2 \mathrm{~A}$ and $\alpha 1 \mathrm{C}$ and Gilles de la Tourette Syndrome. Am. J. Med. Genet. 2003, 119B, 54-59. [CrossRef] [PubMed]

92. Chou, I.-C.; Tsai, C.-H.; Wan, L.; Hsu, Y.-A.; Tsai, F.-J. Association study between Tourette's syndrome and polymorphisms of noradrenergic genes (ADRA2A, ADRA2C). Psychiatr. Genet. 2007, 17, 359. [CrossRef] [PubMed]

93. Janik, P.; Berdyński, M.; Safranow, K.; Żekanowski, C. Association of ADORA1 rs2228079 and ADORA2A rs5751876 Polymorphisms with Gilles de la Tourette Syndrome in the Polish Population. PLoS ONE 2015, 10. [CrossRef] [PubMed]

94. Gade, R.; Muhleman, D.; Blake, H.; MacMurray, J.; Johnson, P.; Verde, R.; Saucier, G.; Comings, D.E. Correlation of length of VNTR alleles at the X-linked MAOA gene and phenotypic effect in Tourette syndrome and drug abuse. Mol. Psychiatry 1998, 3, 50-60. [CrossRef] [PubMed]

95. GWAS Catalog. Available online: http://www.ebi.ac.uk/gwas/ (accessed on 25 July 2017).

96. Schizophrenia Working Group of the Psychiatric Genomics Consortium. Biological insights from 108 schizophrenia-associated genetic loci. Nature 2014, 511, 421-427.

97. Ripke, S.; O’Dushlaine, C.; Chambert, K.; Moran, J.L.; Kähler, A.K.; Akterin, S.; Bergen, S.E.; Collins, A.L.; Crowley, J.J.; Fromer, M.; et al. Genome-wide association analysis identifies 13 new risk loci for schizophrenia. Nat. Genet. 2013, 45, 1150-1159. [CrossRef] [PubMed]

98. Wang, K.; Zhang, H.; Ma, D.; Bucan, M.; Glessner, J.T.; Abrahams, B.S.; Salyakina, D.; Imielinski, M.; Bradfield, J.P.; Sleiman, P.M.; et al. Common genetic variants on 5p14.1 associate with autism spectrum disorders., Common genetic variants on 5p14.1 associate with autism spectrum disorders. Nature 2009, 459, 528-533. [CrossRef] [PubMed]

99. Xia, K.; Guo, H.; Hu, Z.; Xun, G.; Zuo, L.; Peng, Y.; Wang, K.; He, Y.; Xiong, Z.; Sun, L.; et al. Common genetic variants on 1p13.2 associate with risk of autism. Mol. Psychiatry 2014, 19, 1212-1219. [CrossRef] [PubMed]

100. Mühleisen, T.W.; Leber, M.; Schulze, T.G.; Strohmaier, J.; Degenhardt, F.; Treutlein, J.; Mattheisen, M.; Forstner, A.J.; Schumacher, J.; Breuer, R.; et al. Genome-wide association study reveals two new risk loci for bipolar disorder. Nat. Commun. 2014, 5, 3339. [CrossRef] [PubMed]

101. Ikeda, M.; Takahashi, A.; Kamatani, Y.; Okahisa, Y.; Kunugi, H.; Mori, N.; Sasaki, T.; Ohmori, T.; Okamoto, Y.; Kawasaki, H.; et al. A genome-wide association study identifies two novel susceptibility loci and trans population polygenicity associated with bipolar disorder. Mol. Psychiatry 2017. [CrossRef] [PubMed]

102. Hek, K.; Demirkan, A.; Lahti, J.; Terracciano, A.; Teumer, A.; Cornelis, M.C.; Amin, N.; Bakshis, E.; Baumert, J.; Ding, J.; et al. A Genome-Wide Association Study of Depressive Symptoms. Biol. Psychiatry 2013, 73, 667-678. [CrossRef] [PubMed]

103. Direk, N.; Williams, S.; Smith, J.A.; Ripke, S.; Air, T.; Amare, A.T.; Amin, N.; Baune, B.T.; Bennett, D.A.; Blackwood, D.H.R.; et al. An Analysis of Two Genome-wide Association Meta-analyses Identifies a New Locus for Broad Depression Phenotype. Biol. Psychiatry 2017. [CrossRef] [PubMed]

104. Mattheisen, M.; Samuels, J.F.; Wang, Y.; Greenberg, B.D.; Fyer, A.J.; McCracken, J.T.; Geller, D.A.; Murphy, D.L.; Knowles, J.A.; Grados, M.A.; et al. Genome-wide association study in obsessive-compulsive disorder: Results from the OCGAS. Mol. Psychiatry 2015, 20, 337-344. [CrossRef] [PubMed]

105. Stewart, S.E.; Yu, D.; Scharf, J.M.; Neale, B.M.; Fagerness, J.A.; Mathews, C.A.; Arnold, P.D.; Evans, P.D.; Gamazon, E.R.; Osiecki, L.; et al. Genome-wide association study of obsessive-compulsive disorder. Mol. Psychiatry 2013, 18, 788-798. [CrossRef] [PubMed] 
106. Yang, L.; Neale, B.M.; Liu, L.; Lee, S.H.; Wray, N.R.; Ji, N.; Li, H.; Qian, Q.; Wang, D.; Li, J.; et al. Polygenic Transmission and Complex Neuro developmental Network for Attention Deficit Hyperactivity Disorder: Genome-Wide Association Study of Both Common and Rare Variants. Am. J. Med. Genet. B Neuropsychiatr. Genet. 2013, 419-430. [CrossRef] [PubMed]

107. Zayats, T.; Athanasiu, L.; Sonderby, I.; Djurovic, S.; Westlye, L.T.; Tamnes, C.K.; Fladby, T.; Aase, H.; Zeiner, P.; Reichborn-Kjennerud, T.; et al. Genome-Wide Analysis of Attention Deficit Hyperactivity Disorder in Norway. PLoS ONE 2015, 10, e0122501. [CrossRef] [PubMed]

108. Ernst, J.; Kheradpour, P.; Mikkelsen, T.S.; Shoresh, N.; Ward, L.D.; Epstein, C.B.; Zhang, X.; Wang, L.; Issner, R.; Coyne, M.; et al. Systematic analysis of chromatin state dynamics in nine human cell types. Nature 2011, 473, 43-49. [CrossRef] [PubMed]

109. Heidari, N.; Phanstiel, D.H.; He, C.; Grubert, F.; Jahanbani, F.; Kasowski, M.; Zhang, M.Q.; Snyder, M.P. Genome-wide map of regulatory interactions in the human genome. Genome Res. 2014, 24, 1905-1917. [CrossRef] [PubMed]

110. Scharf, J.M.; Yu, D.; Mathews, C.A.; Neale, B.M.; Stewart, S.E.; Fagerness, J.A.; Evans, P.; Gamazon, E.; Edlund, C.K.; Service, S.K.; et al. Genome-wide association study of Tourette's syndrome. Mol. Psychiatry 2013, 18, 721-728. [CrossRef] [PubMed]

111. Paschou, P.; Yu, D.; Gerber, G.; Evans, P.; Tsetsos, F.; Davis, L.K.; Karagiannidis, I.; Chaponis, J.; Gamazon, E.; Mueller-Vahl, K.; et al. Genetic association signal near NTN4 in Tourette syndrome. Ann. Neurol. 2014, 76, 310-315. [CrossRef] [PubMed]

112. Yu, D.; Mathews, C.A.; Scharf, J.M.; Neale, B.M.; Davis, L.K.; Gamazon, E.R.; Derks, E.M.; Evans, P.; Edlund, C.K.; Crane, J.; et al. Cross-Disorder Genome-Wide Analyses Suggest a Complex Genetic Relationship Between Tourette's Syndrome and OCD. AJP 2014, 172, 82-93. [CrossRef] [PubMed]

113. Middeldorp, C.M.; Hammerschlag, A.R.; Ouwens, K.G.; Groen-Blokhuis, M.M.; St. Pourcain, B.; Greven, C.U.; Pappa, I.; Tiesler, C.M.T.; Ang, W.; Nolte, I.M.; et al. A Genome-Wide Association Meta-Analysis of Attention-Deficit/Hyperactivity Disorder Symptoms in Population-Based Pediatric Cohorts. J. Am. Acad. Child Adolesc. Psychiatry 2016, 55, 896-905.e6. [CrossRef] [PubMed]

114. Neale, B.M.; Medland, S.E.; Ripke, S.; Asherson, P.; Franke, B.; Lesch, K.-P.; Faraone, S.V.; Nguyen, T.T.; Schäfer, H.; Holmans, P.; et al. Meta-Analysis of Genome-Wide Association Studies of Attention-Deficit/Hyperactivity Disorder. J. Am. Acad. Child Adolesc. Psychiatry 2010, 49, 884-897. [CrossRef] [PubMed]

115. Hou, L.; Bergen, S.E.; Akula, N.; Song, J.; Hultman, C.M.; Landén, M.; Adli, M.; Alda, M.; Ardau, R.; Arias, B.; et al. Genome-wide association study of 40,000 individuals identifies two novel loci associated with bipolar disorder. Hum. Mol. Genet. 2016, 25, 3383-3394. [CrossRef] [PubMed]

116. Power, R.A.; Tansey, K.E.; Buttenschøn, H.N.; Cohen-Woods, S.; Bigdeli, T.; Hall, L.S.; Kutalik, Z.; Lee, S.H.; Ripke, S.; Steinberg, S.; et al. Genome-wide Association for Major Depression Through Age at Onset Stratification: Major Depressive Disorder Working Group of the Psychiatric Genomics Consortium. Biol. Psychiatry 2017, 81, 325-335. [CrossRef] [PubMed]

117. Direk, N.; Williams, S.; Smith, J.A.; Ripke, S.; Air, T.; Amare, A.T.; Amin, N.; Baune, B.T.; Bennett, D.A.; Blackwood, D.H.R. Meta-analysis of GWAS of over 16,000 individuals with autism spectrum disorder highlights a novel locus at 10q24.32 and a significant overlap with schizophrenia. Mol. Autism 2017. [CrossRef]

118. Cross-Disorder Group of the Psychiatric Genomics Consortium. Identification of risk loci with shared effects on five major psychiatric disorders: A genome-wide analysis. Lancet 2013, 381, 1371-1379.

119. Kajiwara, Y.; Buxbaum, J.D.; Grice, D.E. SLITRK1 Binds 14-3-3 and Regulates Neurite Outgrowth in a Phosphorylation-Dependent Manner. Biol. Psychiatry 2009, 66, 918-925. [CrossRef] [PubMed]

120. Karagiannidis, I.; Rizzo, R.; Tarnok, Z.; Wolanczyk, T.; Hebebrand, J.; Nöthen, M.M.; Lehmkuhl, G.; Farkas, L.; Nagy, P.; Barta, C.; et al. Replication of association between a SLITRK1 haplotype and Tourette Syndrome in a large sample of families. Mol. Psychiatry 2012, 17, 665-668. [CrossRef] [PubMed]

121. Proenca, C.C.; Gao, K.P.; Shmelkov, S.V.; Rafii, S.; Lee, F.S. Slitrks as emerging candidate genes involved in neuropsychiatric disorders. Trends Neurosci. 2011, 34, 143-153. [CrossRef] [PubMed]

122. Patel, C.; Cooper-Charles, L.; McMullan, D.J.; Walker, J.M.; Davison, V.; Morton, J. Translocation breakpoint at 7q31 associated with tics: Further evidence for IMMP2L as a candidate gene for Tourette syndrome. Eur. J. Hum. Genet. 2011, 19, 634-639. [CrossRef] [PubMed] 
123. Bertelsen, B.; Melchior, L.; Jensen, L.R.; Groth, C.; Glenthøj, B.; Rizzo, R.; Debes, N.M.; Skov, L.; Brøndum-Nielsen, K.; Paschou, P.; et al. Intragenic deletions affecting two alternative transcripts of the IMMP2L gene in patients with Tourette syndrome. Eur. J. Hum. Genet. 2014, 22, 1283-1289. [CrossRef] [PubMed]

124. Verkerk, A.J.M.H.; Mathews, C.A.; Joosse, M.; Eussen, B.H.J.; Heutink, P.; Oostra, B.A. Cntnap2 is disrupted in a family with gilles de la tourette syndrome and obsessive compulsive disorder. Genomics 2003, 82, 1-9. [CrossRef]

125. Belloso, J.M.; Bache, I.; Guitart, M.; Caballin, M.R.; Halgren, C.; Kirchhoff, M.; Ropers, H.-H.; Tommerup, N.; Tümer, Z. Disruption of the CNTNAP2 gene in a $t(7 ; 15)$ translocation family without symptoms of Gilles de la Tourette syndrome. Eur. J. Hum. Genet. 2007, 15, 711-713. [CrossRef] [PubMed]

126. Lawson-Yuen, A.; Saldivar, J.-S.; Sommer, S.; Picker, J. Familial deletion within NLGN4 associated with autism and Tourette syndrome. Eur. J. Hum. Genet. 2008, 16, 614-618. [CrossRef] [PubMed]

127. Hooper, S.D.; Johansson, A.C.; Tellgren-Roth, C.; Stattin, E.-L.; Dahl, N.; Cavelier, L.; Feuk, L. Genome-wide sequencing for the identification of rearrangements associated with Tourette syndrome and obsessive-compulsive disorder. BMC Med. Genet. 2012, 13, 123. [CrossRef] [PubMed]

128. Kroisel, P.M.; Petek, E.; Emberger, W.; Windpassinger, C.; Wladika, W.; Wagner, K. Candidate region for Gilles de la Tourette syndrome at 7q31. Am. J. Med. Genet. 2001, 101, 259-261. [CrossRef]

129. Crawford, F.C.; Ait-Ghezala, G.; Morris, M.; Sutcliffe, M.J.; Hauser, R.A.; Silver, A.A.; Mullan, M.J. Translocation breakpoint in two unrelated Tourette syndrome cases, within a region previously linked to the disorder. Hum. Genet. 2003, 113, 154-161. [PubMed]

130. Matsumoto, N.; David, D.E.; Johnson, E.W.; Konecki, D.; Burmester, J.K.; Ledbetter, D.H.; Weber, J.L. Breakpoint sequences of an 1;8 translocation in a family with Gilles de la Tourette syndrome. Eur. J. Hum. Genet. 2000, 8, 875-883. [CrossRef] [PubMed]

131. Taylor, L.D.; Krizman, D.B.; Jankovic, J.; Hayani, A.; Steuber, P.C.; Greenberg, F.; Fenwick, R.G.; Caskey, C.T. 9p monosomy in a patient with Gilles de la Tourette's syndrome. Neurology 1991, 41, 1513. [CrossRef] [PubMed]

132. Bertelsen, B.; Melchior, L.; Jensen, L.R.; Groth, C.; Nazaryan, L.; Debes, N.M.; Skov, L.; Xie, G.; Sun, W.; Brøndum-Nielsen, K.; et al. A t(3;9)(q25.1;q34.3) translocation leading to OLFM1 fusion transcripts in Gilles de la Tourette syndrome, OCD and ADHD. Psychiatry Res. 2015, 225, 268-275. [CrossRef] [PubMed]

133. O’Roak, B.; Morgan, T.; Fishman, D.; Saus, E.; Alonso, P.; Gratacòs, M.; Estivill, X.; Teltsh, O.; Kohn, Y.; Kidd, K.; et al. Additional support for the association of SLITRK1 var321 and Tourette syndrome. Mol. Psychiatry 2010, 15, 447-450. [CrossRef] [PubMed]

134. Melchior, L.; Bertelsen, B.; Debes, N.M.; Groth, C.; Skov, L.; Mikkelsen, J.D.; Brøndum-Nielsen, K.; Tümer, Z. Microduplication of 15q13.3 and Xq21.31 in a family with tourette syndrome and comorbidities. Am. J. Med. Genet. 2013, 162, 825-831. [CrossRef] [PubMed]

135. Jankovic, J.; Deng, H. Candidate Locus for Chorea and Tic Disorders at 15q? Pediatr. Neurol. 2007, 37, 70-73. [CrossRef] [PubMed]

136. Kerbeshian, J.; Severud, R.; Burd, L.; Larson, L. Peek-a-boo fragile site at 16d associated with Tourette syndrome, bipolar disorder, autistic disorder, and mental retardation. Am. J. Med. Genet. 2000, 96, 69-73. [CrossRef]

137. Dehning, S.; Riedel, M.; Müller, N. Father-to-Son Transmission of 6;17 Translocation in Tourette's Syndrome. AJP 2008, 165, 1051-1052. [CrossRef] [PubMed]

138. Shelley, B.P.; Robertson, M.M.; Turk, J. An individual with Gilles de la Tourette syndrome and Smith-Magenis microdeletion syndrome: Is chromosome $17 \mathrm{p} 11.2$ a candidate region for Tourette syndrome putative susceptibility genes? J. Intell. Disabil. Res. 2007, 51, 620-624. [CrossRef] [PubMed]

139. Cuker, A.; State, M.W.; King, R.A.; Davis, N.; Ward, D.C. Candidate locus for Gilles de la Tourette syndrome/obsessive compulsive disorder/chronic tic disorder at 18q22. Am. J. Med. Genet. 2004, 130A, 37-39. [CrossRef] [PubMed]

140. State, M.W.; Greally, J.M.; Cuker, A.; Bowers, P.N.; Henegariu, O.; Morgan, T.M.; Gunel, M.; DiLuna, M.; King, R.A.; Nelson, C.; et al. Epigenetic abnormalities associated with a chromosome 18(q21-q22) inversion and a Gilles de la Tourette syndrome phenotype. Proc. Natl. Acad. Sci. USA 2003, 100, 4684-4689. [CrossRef] [PubMed] 
141. Robertson, M.M.; Shelley, B.P.; Dalwai, S.; Brewer, C.; Critchley, H.D. A patient with both Gilles de la Tourette's syndrome and chromosome 22q11 deletion syndrome: Clue to the genetics of Gilles de la Tourette's syndrome? J. Psychosom. Res. 2006, 61, 365-368. [CrossRef] [PubMed]

142. Sharp, A.J.; Locke, D.P.; McGrath, S.D.; Cheng, Z.; Bailey, J.A.; Vallente, R.U.; Pertz, L.M.; Clark, R.A.; Schwartz, S.; Segraves, R.; et al. Segmental Duplications and Copy-Number Variation in the Human Genome. Am. J. Hum. Genet. 2005, 77, 78-88. [CrossRef] [PubMed]

143. Kotlar, A.V.; Mercer, K.B.; Zwick, M.E.; Mulle, J.G. New discoveries in schizophrenia genetics reveal neurobiological pathways: A review of recent findings. Eur. J. Med. Genet. 2015, 58, 704-714. [CrossRef] [PubMed]

144. Cook, E.H., Jr.; Scherer, S.W. Copy-number variations associated with neuropsychiatric conditions. Nature 2008, 455, 919-923. [CrossRef] [PubMed]

145. Sebat, J.; Lakshmi, B.; Malhotra, D.; Troge, J.; Lese-Martin, C.; Walsh, T.; Yamrom, B.; Yoon, S.; Krasnitz, A.; Kendall, J.; et al. Strong Association of De Novo Copy Number Mutations with Autism. Science 2007, 316, 445-449. [CrossRef] [PubMed]

146. Poultney, C.S.; Goldberg, A.P.; Drapeau, E.; Kou, Y.; Harony-Nicolas, H.; Kajiwara, Y.; De Rubeis, S.; Durand, S.; Stevens, C.; Rehnström, K.; et al. Identification of Small Exonic CNV from Whole-Exome Sequence Data and Application to Autism Spectrum Disorder. Am. J. Hum. Genet. 2013, 93, 607-619. [CrossRef] [PubMed]

147. Ionita-Laza, I.; Xu, B.; Makarov, V.; Buxbaum, J.D.; Roos, J.L.; Gogos, J.A.; Karayiorgou, M. Scan statistic-based analysis of exome sequencing data identifies FAN1 at 15q13.3 as a susceptibility gene for schizophrenia and autism. Proc. Natl. Acad. Sci. USA 2014, 111, 343-348. [CrossRef] [PubMed]

148. Xu, B.; Roos, J.L.; Levy, S.; van Rensburg, E.J.; Gogos, J.A.; Karayiorgou, M. Strong association of de novo copy number mutations with sporadic schizophrenia. Nat. Genet. 2008, 40, 880-885. [CrossRef] [PubMed]

149. Bourgeron, T. Current knowledge on the genetics of autism and propositions for future research. Comptes Rendus Biol. 2016, 339, 300-307. [CrossRef] [PubMed]

150. Fernandez, T.V.; Sanders, S.J.; Yurkiewicz, I.R.; Ercan-Sencicek, A.G.; Kim, Y.-S.; Fishman, D.O.; Raubeson, M.J.; Song, Y.; Yasuno, K.; Ho, W.S.C.; et al. Rare Copy Number Variants in Tourette Syndrome Disrupt Genes in Histaminergic Pathways and Overlap with Autism. Biol. Psychiatry 2012, 71, $392-402$. [CrossRef] [PubMed]

151. Sanders, S.J.; Ercan-Sencicek, A.G.; Hus, V.; Luo, R.; Murtha, M.T.; Moreno-De-Luca, D.; Chu, S.H.; Moreau, M.P.; Gupta, A.R.; Thomson, S.A.; et al. Multiple recurrent de novo copy number variations (CNVs), including duplications of the 7q11.23 Williams-Beuren syndrome region, are strongly associated with autism. Neuron 2011, 70, 863-885. [CrossRef] [PubMed]

152. Sundaram, S.K.; Huq, A.M.; Wilson, B.J.; Chugani, H.T. Tourette syndrome is associated with recurrent exonic copy number variants (e-Pub ahead of print)(CME). Neurology 2010, 74, 1583-1590. [CrossRef] [PubMed]

153. Nag, A.; Bochukova, E.G.; Kremeyer, B.; Campbell, D.D.; Muller, H.; Valencia-Duarte, A.V.; Cardona, J.; Rivas, I.C.; Mesa, S.C.; Cuartas, M.; et al. CNV Analysis in Tourette Syndrome Implicates Large Genomic Rearrangements in COL8A1 and NRXN1. PLoS ONE 2013, 8, e59061. [CrossRef] [PubMed]

154. McGrath, L.M.; Yu, D.; Marshall, C.; Davis, L.K.; Thiruvahindrapuram, B.; Li, B.; Cappi, C.; Gerber, G.; Wolf, A.; Schroeder, F.A.; et al. Copy Number Variation in Obsessive-Compulsive Disorder and Tourette Syndrome: A Cross-Disorder Study. J. Am. Acad. Child Adolesc. Psychiatry 2014, 53, 910-919. [CrossRef] [PubMed]

155. Bertelsen, B.; Stefánsson, H.; Riff Jensen, L.; Melchior, L.; Mol Debes, N.; Groth, C.; Skov, L.; Werge, T.; Karagiannidis, I.; Tarnok, Z.; et al. Association of AADAC Deletion and Gilles de la Tourette Syndrome in a Large European Cohort. Biol. Psychiatry 2016, 79, 383-391. [CrossRef] [PubMed]

156. Huang, A.Y.; Yu, D.; Davis, L.K.; Sul, J.H.; Tsetsos, F.; Ramensky, V.; Zelaya, I.; Ramos, E.M.; Osiecki, L.; Chen, J.A.; et al. Rare Copy Number Variants in NRXN1 and CNTN6 Increase Risk for Tourette Syndrome. Neuron 2017, 94, 1101-1111. [CrossRef] [PubMed]

157. Bamshad, M.J.; Ng, S.B.; Bigham, A.W.; Tabor, H.K.; Emond, M.J.; Nickerson, D.A.; Shendure, J. Exome sequencing as a tool for Mendelian disease gene discovery. Nat. Rev. Genet. 2011, 12, 745-755. [CrossRef] [PubMed] 
158. Kiezun, A.; Garimella, K.; Do, R.; Stitziel, N.O.; Neale, B.M.; McLaren, P.J.; Gupta, N.; Sklar, P.; Sullivan, P.F.; Moran, J.L.; et al. Exome sequencing and the genetic basis of complex traits. Nat. Genet. 2012, 44, 623-630. [CrossRef] [PubMed]

159. Zhang, X. Exome sequencing greatly expedites the progressive research of Mendelian diseases. Front. Med. 2014, 8, 42-57. [CrossRef] [PubMed]

160. Ezewudo, M.; Zwick, M.E. Evaluating Rare Variants in Complex Disorders Using Next-Generation Sequencing. Curr. Psychiatry Rep. 2013, 15, 349. [CrossRef] [PubMed]

161. Choi, M.; Scholl, U.I.; Ji, W.; Liu, T.; Tikhonova, I.R.; Zumbo, P.; Nayir, A.; Bakkaloğlu, A.; Özen, S.; Sanjad, S.; et al. Genetic diagnosis by whole exome capture and massively parallel DNA sequencing. Proc. Natl. Acad. Sci. USA 2009, 106, 19096-19101. [CrossRef] [PubMed]

162. Cappi, C.; Brentani, H.; Lima, L.; Sanders, S.J.; Zai, G.; Diniz, B.J.; Reis, V.N.S.; Hounie, A.G.; Conceição do Rosário, M.; Mariani, D.; et al. Whole-exome sequencing in obsessive-compulsive disorder identifies rare mutations in immunological and neurodevelopmental pathways. Transl. Psychiatry 2016, 6, e764. [CrossRef] [PubMed]

163. Schreiber, M.; Dorschner, M.; Tsuang, D. Next-generation sequencing in schizophrenia and other neuropsychiatric disorders. Am. J. Med. Genet. 2013, 162, 671-678. [CrossRef] [PubMed]

164. Sener, E.F.; Canatan, H.; Ozkul, Y. Recent Advances in Autism Spectrum Disorders: Applications of Whole Exome Sequencing Technology. Psychiatry Investig. 2016, 13, 255-264. [CrossRef] [PubMed]

165. Kato, T. Whole genome/exome sequencing in mood and psychotic disorders. Psychiatry Clin. Neurosci. 2015, 69, 65-76. [CrossRef] [PubMed]

166. De Rubeis, S.; He, X.; Goldberg, A.P.; Poultney, C.S.; Samocha, K.; Cicek, A.E.; Kou, Y.; Liu, L.; Fromer, M.; Walker, S.; et al. Synaptic, transcriptional, and chromatin genes disrupted in autism. Nature 2014, 515, 209-215. [CrossRef] [PubMed]

167. Iossifov, I.; O’Roak, B.J.; Sanders, S.J.; Ronemus, M.; Krumm, N.; Levy, D.; Stessman, H.A.; Witherspoon, K.T.; Vives, L.; Patterson, K.E.; et al. The contribution of de novo coding mutations to autism spectrum disorder. Nature 2014, 515, 216-221. [CrossRef] [PubMed]

168. Sanders, S.J.; He, X.; Willsey, A.J.; Ercan-Sencicek, A.G.; Samocha, K.E.; Cicek, A.E.; Murtha, M.T.; Bal, V.H.; Bishop, S.L.; Dong, S.; et al. Insights into Autism Spectrum Disorder Genomic Architecture and Biology from 71 Risk Loci. Neuron 2015, 87, 1215-1233. [CrossRef] [PubMed]

169. Lim, E.T.; Uddin, M.; De Rubeis, S.; Chan, Y.; Kamumbu, A.S.; Zhang, X.; D'Gama, A.M.; Kim, S.N.; Hill, R.S.; Goldberg, A.P.; et al. Rates, distribution and implications of postzygotic mosaic mutations in autism spectrum disorder. Nat. Neurosci. 2017. [CrossRef] [PubMed]

170. Purcell, S.M.; Moran, J.L.; Fromer, M.; Ruderfer, D.; Solovieff, N.; Roussos, P.; O'Dushlaine, C.; Chambert, K.; Bergen, S.E.; Kähler, A.; et al. A polygenic burden of rare disruptive mutations in schizophrenia. Nature 2014, 506, 185-190. [CrossRef] [PubMed]

171. Singh, T.; Kurki, M.I.; Curtis, D.; Purcell, S.M.; Crooks, L.; McRae, J.; Suvisaari, J.; Chheda, H.; Blackwood, D.; Breen, G.; et al. Rare loss-of-function variants in SETD1A are associated with schizophrenia and developmental disorders. Nat. Neurosci. 2016, 19, 571-577. [CrossRef] [PubMed]

172. Genovese, G.; Fromer, M.; Stahl, E.A.; Ruderfer, D.M.; Chambert, K.; Landén, M.; Moran, J.L.; Purcell, S.M.; Sklar, P.; Sullivan, P.F.; et al. Increased burden of ultra-rare protein-altering variants among 4877 individuals with schizophrenia. Nat. Neurosci. 2016, 19, 1433-1441. [CrossRef] [PubMed]

173. Singh, T.; Walters, J.T.R.; Johnstone, M.; Curtis, D.; Suvisaari, J.; Torniainen, M.; Rees, E.; Iyegbe, C.; Blackwood, D.; McIntosh, A.M.; et al. The contribution of rare variants to risk of schizophrenia in individuals with and without intellectual disability. Nat. Genet. 2017, 49, 1167-1173. [CrossRef] [PubMed]

174. Goes, F.S.; Pirooznia, M.; Parla, J.S.; Kramer, M.; Ghiban, E.; Mavruk, S.; Chen, Y.-C.; Monson, E.T.; Willour, V.L.; Karchin, R.; et al. Exome Sequencing of Familial Bipolar Disorder. JAMA Psychiatry 2016, 73, 590-597. [CrossRef] [PubMed]

175. Rao, A.R.; Yourshaw, M.; Christensen, B.; Nelson, S.F.; Kerner, B. Rare deleterious mutations are associated with disease in bipolar disorder families. Mol. Psychiatry 2016. [CrossRef] [PubMed]

176. Amin, N.; de Vrij, F.M.S.; Baghdadi, M.; Brouwer, R.W.W.; van Rooij, J.G.J.; Jovanova, O.; Uitterlinden, A.G.; Hofman, A.; Janssen, H.L.A.; Darwish Murad, S.; et al. A rare missense variant in RCL1 segregates with depression in extended families. Mol. Psychiatry 2017. [CrossRef] [PubMed] 
177. Amin, N.; Jovanova, O.; Adams, H.H.H.; Dehghan, A.; Kavousi, M.; Vernooij, M.W.; Peeters, R.P.; de Vrij, F.M.S.; van der Lee, S.J.; van Rooij, J.G.J.; et al. Exome-sequencing in a large population-based study reveals a rare Asn396Ser variant in the LIPG gene associated with depressive symptoms. Mol. Psychiatry 2017, 22, 537-543. [CrossRef] [PubMed]

178. Amin, N.; Belonogova, N.M.; Jovanova, O.; Brouwer, R.W.W.; van Rooij, J.G.J.; van den Hout, M.C.G.N.; Svishcheva, G.R.; Kraaij, R.; Zorkoltseva, I.V.; Kirichenko, A.V.; et al. Nonsynonymous Variation in NKPD1 Increases Depressive Symptoms in European Populations. Biol. Psychiatry 2017, 81, 702-707. [CrossRef] [PubMed]

179. Yuen, R.K.C.; Merico, D.; Bookman, M.; Howe, J.L.; Thiruvahindrapuram, B.; Patel, R.V.; Whitney, J.; Deflaux, N.; Bingham, J.; Wang, Z.; et al. Whole genome sequencing resource identifies 18 new candidate genes for autism spectrum disorder. Nat. Neurosci. 2017. [CrossRef]

180. Ament, S.A.; Szelinger, S.; Glusman, G.; Ashworth, J.; Hou, L.; Akula, N.; Shekhtman, T.; Badner, J.A.; Brunkow, M.E.; Mauldin, D.E.; et al. Rare variants in neuronal excitability genes influence risk for bipolar disorder. Proc. Natl. Acad. Sci. USA 2015, 112, 3576-3581. [CrossRef] [PubMed]

181. Homann, O.R.; Misura, K.; Lamas, E.; Sandrock, R.W.; Nelson, P.; McDonough, S.I.; DeLisi, L.E. Whole-genome sequencing in multiplex families with psychoses reveals mutations in the SHANK2 and SMARCA1 genes segregating with illness. Mol. Psychiatry 2016, 21, 1690-1695. [CrossRef] [PubMed]

182. Consortium, C. Sparse whole genome sequencing identifies two loci for major depressive disorder. Nature 2015, 523, 588-591.

183. Drögemöller, B. Whole-genome sequencing provides insight into the genetics of major depressive disorder. Clin. Genet. 2015, 88, 340-342. [CrossRef] [PubMed]

184. Peterson, R.E.; Cai, N.; Bigdeli, T.B.; Li, Y.; Reimers, M.; Nikulova, A.; Webb, B.T.; Bacanu, S.-A.; Riley, B.P.; Flint, J.; et al. The Genetic Architecture of Major Depressive Disorder in Han Chinese Women. JAMA Psychiatry 2017, 74, 162-168. [CrossRef] [PubMed]

185. Cai, N.; Bigdeli, T.B.; Kretzschmar, W.W.; Li, Y.; Liang, J.; Hu, J.; Peterson, R.E.; Bacanu, S.; Webb, B.T.; Riley, B.; et al. 11,670 whole-genome sequences representative of the Han Chinese population from the CONVERGE project. Sci. Data 2017. [CrossRef] [PubMed]

186. Dong, S.; Walker, M.F.; Carriero, N.J.; DiCola, M.; Willsey, A.J.; Ye, A.Y.; Waqar, Z.; Gonzalez, L.E.; Overton, J.D.; Frahm, S.; et al. De novo insertions and deletions of predominantly paternal origin are associated with autism spectrum disorder. Cell Rep. 2014, 9, 16-23. [CrossRef] [PubMed]

187. Xu, B.; Ionita-Laza, I.; Roos, J.L.; Boone, B.; Woodrick, S.; Sun, Y.; Levy, S.; Gogos, J.A.; Karayiorgou, M. De novo gene mutations highlight patterns of genetic and neural complexity in schizophrenia. Nat. Genet. 2012, 44, 1365-1369. [CrossRef] [PubMed]

188. Takata, A.; Ionita-Laza, I.; Gogos, J.A.; Xu, B.; Karayiorgou, M. De Novo Synonymous Mutations in Regulatory Elements Contribute to the Genetic Etiology of Autism and Schizophrenia. Neuron 2016, 89, 940-947. [CrossRef] [PubMed]

189. Kataoka, M.; Matoba, N.; Sawada, T.; Kazuno, A.-A.; Ishiwata, M.; Fujii, K.; Matsuo, K.; Takata, A.; Kato, T. Exome sequencing for bipolar disorder points to roles of de novo loss-of-function and protein-altering mutations. Mol. Psychiatry 2016, 21, 885-893. [CrossRef] [PubMed]

190. Adamsen, D.; Ramaekers, V.; Ho, H.T.; Britschgi, C.; Rüfenacht, V.; Meili, D.; Bobrowski, E.; Philippe, P.; Nava, C.; Van Maldergem, L.; et al. Autism spectrum disorder associated with low serotonin in CSF and mutations in the SLC29A4 plasma membrane monoamine transporter (PMAT) gene. Mol. Autism 2014, 5, 43. [CrossRef] [PubMed]

191. Fromer, M.; Pocklington, A.J.; Kavanagh, D.H.; Williams, H.J.; Dwyer, S.; Gormley, P.; Georgieva, L.; Rees, E.; Palta, P.; Ruderfer, D.M.; et al. De novo mutations in schizophrenia implicate synaptic networks. Nature 2014, 506, 179-184. [CrossRef] [PubMed]

192. Schaaf, C.P.; Gonzalez-Garay, M.L.; Xia, F.; Potocki, L.; Gripp, K.W.; Zhang, B.; Peters, B.A.; McElwain, M.A.; Drmanac, R.; Beaudet, A.L.; et al. Truncating mutations of MAGEL2cause Prader-Willi phenotypes and autism. Nat. Genet. 2013, 45, 1405-1408. [CrossRef] [PubMed]

193. Iossifov, I.; Ronemus, M.; Levy, D.; Wang, Z.; Hakker, I.; Rosenbaum, J.; Yamrom, B.; Lee, Y.; Narzisi, G.; Leotta, A.; et al. De Novo Gene Disruptions in Children on the Autistic Spectrum. Neuron 2012, 74, 285-299. [CrossRef] [PubMed] 
194. McCarthy, S.E.; Gillis, J.; Kramer, M.; Lihm, J.; Yoon, S.; Berstein, Y.; Mistry, M.; Pavlidis, P.; Solomon, R.; Ghiban, E.; et al. De novo mutations in schizophrenia implicate chromatin remodeling and support a genetic overlap with autism and intellectual disability. Mol. Psychiatry 2014, 19, 652-658. [CrossRef] [PubMed]

195. Li, J.; Cai, T.; Jiang, Y.; Chen, H.; He, X.; Chen, C.; Li, X.; Shao, Q.; Ran, X.; Li, Z.; et al. Genes with de novo mutations are shared by four neuropsychiatric disorders discovered from NPdenovo database. Mol. Psychiatry 2016, 21, 290-297. [CrossRef] [PubMed]

196. Merico, D.; Zarrei, M.; Costain, G.; Ogura, L.; Alipanahi, B.; Gazzellone, M.J.; Butcher, N.J.; Thiruvahindrapuram, B.; Nalpathamkalam, T.; Chow, E.W.C.; et al. Whole-Genome Sequencing Suggests Schizophrenia Risk Mechanisms in Humans with 22q11.2 Deletion Syndrome. G3 2015, 5, 2453-2461. [CrossRef] [PubMed]

197. Fiorentino, A.; O’Brien, N.L.; Locke, D.P.; McQuillin, A.; Jarram, A.; Anjorin, A.; Kandaswamy, R.; Curtis, D.; Blizard, R.A.; Gurling, H.M.D. Analysis of ANK3 and CACNA1C variants identified in bipolar disorder whole genome sequence data. Bipolar Disord. 2014, 16, 583-591. [CrossRef] [PubMed]

198. Ross, J.; Gedvilaite, E.; Badner, J.A.; Erdman, C.; Baird, L.; Matsunami, N.; Leppert, M.; Xing, J.; Byerley, W. A Rare Variant in CACNA1D Segregates with 7 Bipolar I Disorder Cases in a Large Pedigree. Mol. Neuropsychiatry 2016, 2, 145-150. [CrossRef] [PubMed]

199. Sundaram, S.K.; Huq, A.M.; Sun, Z.; Yu, W.; Bennett, L.; Wilson, B.J.; Behen, M.E.; Chugani, H.T. Exome sequencing of a pedigree with tourette syndrome or chronic tic disorder. Ann. Neurol. 2011, 69, 901-904. [CrossRef] [PubMed]

200. Willsey, A.J.; Fernandez, T.V.; Yu, D.; King, R.A.; Dietrich, A.; Xing, J.; Sanders, S.J.; Mandell, J.D.; Huang, A.Y.; Richer, P.; et al. De Novo Coding Variants Are Strongly Associated with Tourette Disorder. Neuron 2017, 94, 486-499. [CrossRef] [PubMed]

201. Eriguchi, Y.; Kuwabara, H.; Inai, A.; Kawakubo, Y.; Nishimura, F.; Kakiuchi, C.; Tochigi, M.; Ohashi, J.; Aoki, N.; Kato, K.; et al. Identification of candidate genes involved in the etiology of sporadic Tourette syndrome by exome sequencing. Am. J. Med. Genet. 2017, 174, 712-723. [CrossRef] [PubMed]

202. Sun, N.; Nasello, C.; Deng, L.; Wang, N.; Zhang, Y.; Xu, Z.; Song, Z.; Kwan, K.; King, R.A.; Pang, Z.P.; et al. The PNKD gene is associated with Tourette Disorder or Tic disorder in a multiplex family. Mol. Psychiatry 2017. [CrossRef] [PubMed]

203. Inbar-Feigenberg, M.; Choufani, S.; Butcher, D.T.; Roifman, M.; Weksberg, R. Basic concepts of epigenetics. Fertil. Steril. 2013, 99, 607-615. [CrossRef] [PubMed]

204. Pagliaroli, L.; Vető, B.; Arányi, T.; Barta, C. From Genetics to Epigenetics: New Perspectives in Tourette Syndrome Research. Front. Neurosci. 2016. [CrossRef] [PubMed]

205. Shorter, K.R.; Miller, B.H. Epigenetic Mechanisms in Schizophrenia. Prog. Biophys. Mol. Biol. 2015, 118, 1-7. [CrossRef] [PubMed]

206. Abdolmaleky, H.M.; Zhou, J.-R.; Thiagalingam, S. An update on the epigenetics of psychotic diseases and autism. Epigenomics 2015, 7, 427-449. [CrossRef] [PubMed]

207. Yao, B.; Jin, P. Unlocking epigenetic codes in neurogenesis. Genes Dev. 2014, 28, 1253-1271. [CrossRef] [PubMed]

208. Bohacek, J.; Gapp, K.; Saab, B.J.; Mansuy, I.M. Transgenerational Epigenetic Effects on Brain Functions. Biol. Psychiatry 2013, 73, 313-320. [CrossRef] [PubMed]

209. Rizzo, R.; Ragusa, M.; Barbagallo, C.; Sammito, M.; Gulisano, M.; Calì, P.V.; Pappalardo, C.; Barchitta, M.; Granata, M.; Condorelli, A.G.; et al. Circulating miRNAs profiles in tourette syndrome: Molecular data and clinical implications. Mol. Brain 2015. [CrossRef] [PubMed]

210. Müller-Vahl, K.R.; Loeber, G.; Kotsiari, A.; Müller-Engling, L.; Frieling, H. Gilles de la Tourette syndrome is associated with hypermethylation of the dopamine D2 receptor gene. J. Psychiatr. Res. 2017, 86, 1-8. [CrossRef] [PubMed]

211. Zilhão, N.R.; Padmanabhuni, S.S.; Pagliaroli, L.; Barta, C.; Smit, D.J.A.; Cath, D.; Nivard, M.G.; Baselmans, B.M.L.; van Dongen, J.; Paschou, P.; et al. Epigenome-Wide Association Study of Tic Disorders. Twin Res. Hum. Genet. 2015, 18, 699-709. [CrossRef] [PubMed]

212. Delgado, M.S.; Camprubí, C.; Tümer, Z.; Martínez, F.; Milà, M.; Monk, D. Screening individuals with intellectual disability, autism and Tourette's syndrome for KCNK9 mutations and aberrant DNA methylation within the 8q24 imprinted cluster. Am. J. Med. Genet. 2014, 165, 472-478. [CrossRef] [PubMed] 
213. Hoekstra, P.J.; Dietrich, A.; Edwards, M.J.; Elamin, I.; Martino, D. Environmental factors in Tourette syndrome. Neurosci. Biobehav. Rev. 2013, 37, 1040-1049. [CrossRef] [PubMed]

214. Chao, T.-K.; Hu, J.; Pringsheim, T. Prenatal risk factors for Tourette Syndrome: A systematic review. BMC Pregnancy Childbirth 2014, 14, 53. [CrossRef] [PubMed]

215. Tourette Syndrome Association International Consortium for Genetics (TSAICG). Available online: https: / / www.findtsgene.org (accessed on 18 October 2017).

216. Tourette International Collaborative Genetics (TIC genetics). Available online: https://tic-genetics.org (accessed on 18 October 2017).

217. European Multicentre Tics in Children (EMTICS). Available online: http://emtics.eu/ (accessed on 18 October 2017).

218. Georgitsi, M.; Willsey, A.J.; Mathews, C.A.; State, M.; Scharf, J.M.; Paschou, P. The Genetic Etiology of Tourette Syndrome: Large-Scale Collaborative Efforts on the Precipice of Discovery. Front. Neurosci. 2016. [CrossRef] [PubMed]

219. TS-EUROTRAIN. Available online: http:/ / ts-eurotrain.eu/ (accessed on 18 October 2017).

220. Akbarian, S.; Liu, C.; Knowles, J.A.; Vaccarino, F.M.; Farnham, P.J.; Crawford, G.E.; Jaffe, A.E.; Pinto, D.; Dracheva, S.; Geschwind, D.H.; et al. The PsychENCODE project. Nat. Neurosci. 2015, 18, 1707-1712. [CrossRef] [PubMed]

221. Gagliano, S.A. It's All in the Brain: A Review of Available Functional Genomic Annotations. Biol. Psychiatry 2017, 81, 478-483. [CrossRef] [PubMed]

(C) 2017 by the authors. Licensee MDPI, Basel, Switzerland. This article is an open access article distributed under the terms and conditions of the Creative Commons Attribution (CC BY) license (http:/ / creativecommons.org/licenses/by/4.0/). 